\title{
BOOK-TAX DIFFERENCES ANORMAIS, SUAVIZAÇÃO DOS RESULTADOS E REAL EARNINGS MANAGEMENT EM EMPRESAS DE CAPITAL ABERTO LISTADAS NO BRASIL
}

\section{ABNORMAL BOOK-TAX DIFFERENCES, INCOME SMOOTHING AND REAL EARNINGS MANAGEMENT IN LISTED COMPANIES IN BRAZIL \\ BOOK-TAX DIFFERENCES ANORMALES, SUAVIZACIÓN DE GANANCÍAS \\ $Y$ GESTIÓN DE GANANCIAS REALES EN EMPRESAS COTIZADAS EN BRASIL}

Recebido em: 03-12-2019

Avaliado em: 01-03-2020

Reformulado em: 01-04-2020

Aceito para publicação em: 11-05-2020

Publicado em: 21-04-2021

Editor Responsável: Roberto Carlos Klann
Bruna Duarte Stoduto ${ }^{1}$

Laís de Araújo Rezende ${ }^{2}$

Antônio Carlos Brunozi Júnior ${ }^{3}$

\section{RESUMO}

As diferenças nas apurações do Lucro Contábil e do Lucro Tributário, denominadas de Book-Tax Differences (BTD), possuem papel informativo para as empresas, e isso permitiu que os estudos as relacionassem com a qualidade dos lucros. No entanto, os resultados foram limitados, pois não houve a consideração de que as $B T D$ são formadas por diferentes componentes, de heterogêneas razões legítimas normativas e questionáveis: as BTD Normais e as BTD Anormais. As BTD Anormais, foco desta pesquisa, que são consequências do gerenciamento de resultados, apresentam argumentos teóricos, da assimetria de informações, mais concretos para justificar a sua associação com a qualidade dos lucros nas empresas, pois não necessariamente os gestores estão alinhados aos interesses dos acionistas. Diante disso, este estudo teve como objetivo analisar as relações entre as BTD Anormais e a suavização dos resultados e o real earnings management em empresas de capital aberto listadas no Brasil. Essas relações são originais academicamente, no Brasil, e têm relevância para a área contábil, devido às mudanças advindas com as IFRS nas normativas da Contabilidade Financeira e Fiscal. Metodologicamente, foram utilizadas 327 empresas listadas na B3, no período de 2010 a 2018, com a aplicação da técnica de dados em painel quantílica. Nos resultados, indicouse que ocorrem mais práticas de suavização dos resultados e de real earnings management a partir das BTD Anormais. Em meios gerais, o estudo reforçou que as BTD, a partir de seus elementos discricionários, são meios para que os gestores realizem a manipulação das informações contábeis, causando assimetria informacional.

Palavras-chave: Book-Tax Differences. BTD Anormais. Suavização dos Resultados. Real Earnings Management.

\footnotetext{
1 Graduanda em Ciências Contábeis pela Universidade Federal de Viçosa (UFV); E-mail: brunadstoduto@gmail.com

${ }^{2}$ Graduanda em Ciências Contábeis pela Universidade Federal de Viçosa (UFV); E-mail: laisrezennde@ outlook.com

3 Doutor em Ciências Contábeis pela Universidade do Vale do Rio dos Sinos (UNISINOS). Docente do Departamento de Administração e Contabilidade da Universidade Federal de Viçosa (UFV); E-mail: acbrunozi@yahoo.com.br
} 


\begin{abstract}
The differences in the accounting earnings and tax earnings, called Book-Tax Differences (BTD), have an informative role for companies, allowing the studies to relate her with the earnings quality. However, the results were limited as there was no consideration that BTD consists of different components of the heterogeneous legitimate normative and questionable reasons, the Normal BTD and Abnormal BTD. Abnormal BTD, the focus of this research, which is consequences of earnings management as they present theoretical arguments of the information asymmetry, are more concrete to justify their association with the companies' earnings quality because managers are not necessarily aligned with the interest of shareholders. Therefore, this study aims to analyze the relationship of abnormal BTD, income smoothing, and real earnings management in Brazilian listed companies. In Brazil, these relationships are original academically and have relevance to the accounting area due to changes with the IFRS in Financial and Tax Accounting. Methodologically, 327 companies listed in B3 were used, from 2010 to 2018, using the quantile panel data technique. The results indicated that income smoothing and real earnings management practices occur from abnormal BTD. In general, the study reinforced that BTD, from their discretionary elements, means managers can manipulate accounting information, causing information asymmetry.
\end{abstract}

Keywords: Book-Tax Differences. Abnormal BTD. Income Smoothing. Real Earnings Management.

\title{
RESUMEN
}

Las diferencias en los cálculos de resultados contables y resultados fiscales, llamadas Book-Tax Differences (BTD), tienen un papel informativo para las empresas y esto permitió que los estudios relacionaran las con la calidad de los resultados. Sin embargo, los resultados fueron limitados ya que no se consideró que los BTD constaran de diferentes componentes, de heterogéneas razones normativas legítimas y cuestionables, las BTD normales y BTD anormales. La consideración de BTD anormales es el enfoque de esta propuesta, que son consecuencias de la gestión de los resultados, ya que presenta argumentos teóricos más concretos, la asimetría de información, para justificar su asociación con la calidad de los resultados, porque los gestores no están necesariamente alineados con los intereses de los accionistas. Dado esto, este estudio tiene como objetivo analizar las relaciones existentes de BTD Anormales en la suavización de ganancias y la gestión de ganancias reales en las empresas que cotizan en bolsa de Brasil. Estas relaciones son académicamente originales en Brasil y tienen relevancia para el área contable debido a cambios con las NIIF en las regulaciones de Contabilidad Financiera e Impuestos. Metodológicamente, se utilizaron 327 empresas que figuran en B3, de 2010 a 2018, con la aplicación de la técnica de datos de panel cuantil. En los resultados, se indicó que hay más prácticas de suavización de ganancias y gestión de ganancias reales basadas en BTD anormales. En general, el estudio reforzó que las BTD, con sus elementos discrecionales, son medios para que los gerentes manipulen la información contable que causa asimetría de la información.

Palabras-clave: Book-Tax Differences. BTD Anormales. Suavización de resultados. Gestión de ingresos reales.

\section{INTRODUÇÃO}

As Book-Tax Differences (BTD), compreendidas como as diferenças periódicas entre o lucro contábil (LC) e o lucro tributário (LT), tornaram-se tema relevante a partir do final da década de 1990 e início dos anos 2000, principalmente na Europa e nos Estados Unidos. Desde então, são objeto de estudo na área acadêmica, estando, inclusive, relacionadas à qualidade dos resultados contábeis (Blaylock, Gaertner, \& Shevlin, 2015; Hanlon, 2005). Nos Estados Unidos, os principais fatores que 
elevaram o assunto como de interesse foram as mudanças ocorridas na legislação tributária do país (Hanlon, 2005), além dos escândalos contábeis em empresas, como Enron, Xerox e Tycon (Lev \& Nissim, 2004). Segundo Hanlon (2005), nos escândalos contábeis foi reconhecido o papel informativo das $B T D$, a partir da diferença em US\$ bilhões entre os resultados reportados e os corretos que deveriam ser elaborados de acordo com as normas de Contabilidade. Como exemplo, tem-se o ocorrido com a empresa Enron, cujos lucros tributários reportados foram reduzidos em U\$5,8 bilhões, em comparação ao que deveria ser corretamente apurado.

A partir do cenário apresentado, estudos acerca das BTD se expandiram, principalmente em virtude do seu papel informativo. A discricionariedade e as lacunas permitidas com os padrões contábeis devido ao regime de competência e os accruals, bem como a rigidez da legislação tributária e a tendência para o pagamento de menos tributos nas empresas, contextualizam as BTD para causar influências na qualidade dos resultados contábeis (Blaylock, Shevlin, \& Wilson, 2012; Brunozi Júnior, 2016). Considerando isso, diversas características da Earnings Quality foram consideradas nessa relação com as BTD: persistência e previsibilidade dos lucros (Hanlon, 2005; Lev \& Nissim, 2004), suavização (Francis, LaFond, Olsson, \& Schipper, 2004; Kolozsvari \& Macedo, 2016), conservadorismo (Jarboui \& Koubaa, 2017) e o earnings management (Blaylock et al., 2015; Ferreira, Martinez, Costa, \& Passamani, 2012; Furtado, Souza, \& Sarlo Neto, 2016).

Apesar da relevância do tema, nos estudos iniciais apresentaram-se lacunas no cálculo das $B T D$, como relatado por Tang (2006), pela não consideração dos diferentes componentes que fazem parte delas, realizando-se apenas a diferença total entre o lucro contábil e o tributário. Dessa forma, os resultados encontrados foram limitados. Diante dessa realidade, Tang (2006) e Tang e Firth (2011) propuseram uma complementação ao conceito das $B T D$, demonstrando que elas são compostas por dois elementos: $B T D$ Normais e $B T D$ Anormais. As primeiras dizem respeito à parcela não discricionária, ou seja, ocorrem devido às divergências entre as normas contábeis e as tributárias (razões normativas legítimas). Por outro lado, as BTD Anormais, foco deste estudo, são caracterizadas como consequência da presença de componentes mais prováveis de práticas de gerenciamento de resultados (razões questionáveis) (Ferreira et al., 2012; Martinez \& Passamani, 2014; Martinez \& Souza, 2015; Kraft, 2015).

As relações entre as BTD Anormais e a qualidade dos lucros sustentam-se pela Teoria de Agência, com os pressupostos dos diferentes interesses entre os principais e os agentes pela assimetria de informações. Dessa forma, aspectos da Earnings Quality, ao refletirem o desempenho econômico da entidade e serem importantes ferramentas para a tomada de decisão, podem ser afetados pelas $B T D$ Anormais, como a suavização dos resultados e o real earnings management, os quais serão considerados para este estudo (Dechow, Ge, \& Schrand, 2010; Ferreira et al., 2012; Roychowdhury, 2006; Tang \& Firth, 2011).

O gerenciamento de resultados relaciona-se com a prática de manipulação das informações contábeis a partir de ações discricionárias adotadas pelos gestores das entidades (Ferreira et al., 2012; Healy \& Wahlen, 1999). Uma de suas formas, o real earnings management, ou gerenciamento de resultados por decisões operacionais, ocorre quando há alterações no sistema contábil no que diz respeito à tempestividade das operações e apresentação do fluxo de caixa das atividades de produção, custos e despesas, repercutindo em uma performance econômica contestável (Katz, 2009; Roychowdhury, 2006; Zang, 2012).

Outrossim, a suavização dos resultados é considerada uma modalidade do earnings management, refletindo os interesses dos gestores ao reportarem as informações de acordo com suas necessidades (Francis et al., 2004; Kazemi \& Nouri, 2012; Kolozsvari \& Macedo, 2016). Ao constituir-se como uma forma de ofuscamento dos resultados (Leuz, Nanda, \& Wisocki, 2003), a suavização pode comprometer a conformidade Book-Tax, assim como as demais maneiras de gerenciamento (Blaylock et al., 2015).

Diante do cenário exposto, indaga-se: Qual o reflexo das BTD Anormais na suavização dos resultados e no real earnings management em empresas de capital aberto listadas no Brasil? Assim, 
a pesquisa teve como objetivo analisar as relações entre as BTD Anormais e a suavização dos resultados e o real earnings management em empresas de capital aberto listadas no Brasil.

O cenário nacional apresenta-se favorável ao contexto em que a temática se insere. A Contabilidade no Brasil evoluiu tardiamente, com a primeira Lei das Sociedades por Ações somente em 1940. Até a década de 1990, no país, a Contabilidade era voltada exclusivamente ao normativo fiscal. Esse cenário somente se modificou com a adoção das International Financial Reporting Standards (IFRS) em 2008, em que as normativas contábeis passaram a considerar a essência sobre a forma das operações. No entanto, as IFRS podem não ter sido adotadas adequadamente e efetivamente no Brasil, pois, no país, o histórico ainda é de prevalência da natureza Code-Law do sistema contábil, com a formação e preferência dos profissionais por práticas voltadas às normas (Joia \& Nakao, 2014). Ademais, mesmo após a adoção das IFRS, estudiosos (Kajimoto \& Nakao, 2018; Marques, Nakao, \& Costa, 2017; Costa, 2012; Nakao, 2012) constataram uma evolução contínua das magnitudes das BTD no Brasil.

Quanto às contribuições teóricas, pode-se apontar: i) houve adições à escassa literatura nacional; não se constataram pesquisas que associaram as BTD Anormais com o real earnings management, bem como são incipientes as conclusões sobre as associações com a suavização dos resultados. Esses tipos de estudo foram sugeridos por Brunozi Júnior (2016) e Nakao (2012); ii) constataram-se poucas pesquisas com a consideração das BTD Anormais e sua relação com a qualidade dos lucros no Brasil. Duas explicações são factíveis: a) facilidade no cálculo e entendimento das BTD totais, subtração do lucro contábil (LC) e lucro tributário (LT), e b) utilização dessa medida com outros interesses pelos pesquisadores, como nas associações com: honorários de auditoria (Ávila, 2016), níveis de governança da B3 (Onezorge \& Teixeira, 2016) e estrutura de capital (Pinto \& Costa, 2019); iii) este estudo trouxe inclusões às pesquisas de Pinto e Costa (2019), Martinez e Massamani (2014) e Piqueiras (2010), a exemplo do cálculo das BTD Anormais, uma vez que houve a consideração de operações relacionadas aos resultados de equivalência patrimonial e juros sobre o capital próprio, importantes explicações para essa diferença Book-Tax; e iv) a consideração de real earnings management inclui as atividades operacionais no rol de explicações sobre a qualidade dos lucros, solicitada em estudos como o de Dechow et al. (2010). O gerenciamento de resultados por atividades operacionais, em vez dos accruals, permite aplicar as práticas de modificação dos resultados pelos gestores por meio do fluxo de caixa operacional, dos descontos nos preços para aumentar temporariamente as vendas, da superprodução para relatar menor custo das mercadorias vendidas e do (des)investimento em pesquisa e desenvolvimento para melhorar o resultado, por exemplo (Roychowdhury, 2006).

Há ainda de se mencionar a relevância deste estudo fora do ambiente acadêmico. O mercado de capitais no Brasil é pequeno e instável, com as informações contábeis sendo reconhecidas assimetricamente em alguns momentos. Entender as BTD pelos seus componentes é compreender seu papel informativo para os acionistas. Normalmente, as BTD totais são conhecidas pelos usuários das informações, mas pouco são reconhecidos os atributos de gerenciamento de resultados nas BTD Anormais. Assim, esta pesquisa é um meio de discussão sobre se a conformidade financeira e fiscal é favorável ou não aos países, pela sua abrangência na assimetria informacional e na qualidade dos lucros (Hanlon, 2005).

\section{REFERENCIAL TEÓRICO}

\subsection{Book-Tax Differences (BTD)}

Conforme Tang e Firth (2011), as Book-Tax Differences (BTD) são definidas como as diferenças entre o lucro contábil e o lucro tributário de uma entidade. Elas existem, primeiramente, devido à divergência entre a legislação tributária e a normativa contábil (Koubaa \& Anis, 2015). Os princípios contábeis geralmente aceitos $(G A A P)$ são as fontes para obter os resultados contábeis das 
organizações, enquanto o lucro tributário pauta-se na legislação tributária em vigência no país (Ferreira et al., 2012). Logo, as formas de apuração seguem origens e utilidades distintas.

Quanto aos GAAP, eles possuem como principal característica o regime de competência para o reconhecimento contábil, ou seja, por meio da ocorrência do fato gerador. No código fiscal, os impostos sobre o lucro também se utilizam do mesmo regime, mas em alguns casos, como em operações de lucros ou rendimentos no exterior específicos, métodos de avaliação de estoques, variações cambiais e provisões, não é permitido o lançamento nas demonstrações anteriormente à percepção de fato dos débitos e créditos, baseando-se no regime de caixa (Drake, 2013). Nessa perspectiva, a Contabilidade, por meio das demonstrações contábeis, é o principal meio de análise da situação econômica e financeira de uma entidade e, para isso, precisa utilizar e evidenciar informações tributárias. Portanto, embora apresentem aspectos distintos, as Ciências Contábeis e o Direito Tributário são áreas dependentes (Koubaa \& Anis, 2015).

Sobre essas diferenças normativas ou "normais" das BTD, segundo Ferreira et al. (2012), há duas classificações que envolvem a temporalidade e o reconhecimento das receitas ou despesas: permanentes ou temporárias. As BTD temporárias referem-se aos distintos momentos de reconhecimento das receitas ou despesas abordadas pelas normas contábeis e legislações tributárias. Nas $B T D$ permanentes, tem-se a premissa de um tipo de legislação não certificar o reconhecimento de certas receitas ou despesas em face da outra (Drake, 2013; Ferreira et al., 2012).

As BTD temporárias e permanentes podem, ainda, ser positivas ou negativas, cujas nomenclaturas referem-se ao resultado entre o lucro contábil e o tributário, se LC $>$ LT ou LC $<$ LT (Hanlon, 2005). Ademais, as BTD podem ser divididas em Normais (parcela não discricionária) e Anormais (parcela discricionária). As primeiras possuem como causa as divergências entre as regras contábeis e as tributárias (razão normativa legítima); já as segundas são consequência da atuação do gestor ao fazer uso do gerenciamento de resultados ou agressividade fiscal, principalmente ao reduzir o lucro tributário e potencializar o contábil (razão questionável) (Ferreira et al., 2012; Kraft, 2015).

No que se refere às $B T D$ Anormais, foco deste estudo, elas podem ter como principal causa o gerenciamento de resultados, como é o caso de uma estratégia de planejamento tributário, a fim de diminuir a carga de impostos incidentes (Martinez \& Souza, 2015). No Brasil, por exemplo, devido à baixa transparência informacional e às tendências para a evasão fiscal (Miller \& Martinez, 2016), essas práticas de BTD Anormais são recorrentes (Chen, Gavious, \& Yosef, 2013). Discorre-se que a flexibilidade e a discricionariedade permitidas pelos pronunciamentos e normas vigentes da Contabilidade Financeira, as quais possibilitam aos gestores gerar informações não adequadas, podem acarretar BTD Anormais devido à rigidez da legislação fiscal, como, por exemplo, em práticas de avaliação de ativos (Tang \& Firth, 2011).

A flexibilidade e a discricionariedade visam uma melhor adequação do gestor para com a realidade econômica das atividades desenvolvidas por determinada entidade e podem ser entendidas como uma conquista na área contábil, no intuito de obter mais qualidade da informação, mas possibilitam ao gestor fornecer dados que não são corretos, repercutindo nas BTD Anormais referidas (Koubaa \& Anis, 2015). Diante disso, conforme Zhou (2016), pode-se concluir que as BTD Anormais são atenuadas pelo nível de planejamento e decisões operacionais das entidades.

Com as definições sobre as $B T D$, é importante discutir que elas possuem utilidade no que diz respeito à apuração do gerenciamento de resultados (Kraft, 2015), além de colaborarem para o proveito das informações contábeis aos investidores e demais usuários (Martinez \& Bassetti, 2016), ao constituírem fonte de conhecimentos futuros (Chi, Pincus, \& Teoh, 2014). A diferença entre o lucro contábil e o lucro fiscal permite avaliar a qualidade dos lucros (ou resultados contábeis) elaborados e divulgados pela entidade (Ferreira et al., 2012), que também varia de acordo com o ciclo de vida em que se encontra a entidade em análise (Martinez \& Bassetti, 2016). Portanto, segundo Tang e Firth (2011), as BTD não só evidenciam a discrepância existente, como também as estratégias relativas à gestão. 
Sobre isso, estudos recentes relacionaram as BTD com diferentes aspectos do mercado financeiro e da informação contábil. Kraft (2015) analisou as BTD Anormais no que se refere à evidenciação de gerenciamento de resultados e previsões de ganhos. $\mathrm{O}$ autor concluiu que as BTD são medidas úteis para a detecção de tais práticas. Martinez e Souza (2015), em seu estudo a respeito das $B T D$, persistência dos lucros e planejamento tributário no âmbito do mercado de empresas brasileiras de capital aberto, demonstraram que essa medida fornece informações necessárias para a análise dos accruals, os quais são fontes de previsibilidade da persistência dos ganhos. Por sua vez, Chi et al. (2014) trabalharam com as perspectivas de book income e taxable income quando temporários. Eles evidenciaram que essas informações, quando relacionadas, são capazes de fornecer conhecimento acerca dos retornos anormais e crescimentos de lucros em um âmbito temporal futuro. Ademais, podem-se ainda citar os estudos de: Tang (2015); Blaylock et al. (2015); Blackburne e Blouin (2016); Zhou (2016); e Jarboui e Koubaa (2017).

\subsection{Earnings Quality}

Earnings Quality, ou qualidade dos resultados contábeis (ou dos lucros), é um conceito que envolve indicadores que refletem o desempenho financeiro e informacional, atual e futuro, de determinada entidade, a partir de dados relevantes para a tomada de decisão, os quais são mensurados pela Contabilidade em um contexto específico (Carvalho, Camargo, \& Kalatzis, 2017; Dechow et al., 2010). As medidas de qualidade dos lucros são estimadas a partir de relatórios anuais ou trimestrais, não sendo aplicadas em intervalos curtos, o que permite uma análise comparativa de dados recentes e anteriores (Ecker, Francis, Kim, Olsson, \& Schipper, 2008). Tais informações promovem o conhecimento, por exemplo, de fluxos futuros de dividendos, o que corrobora a importância dessa medida para os usuários da informação contábil (Silva, Bonfim, Niyama, \& Silva, 2017). Dessa forma, o Earnings Quality relaciona-se com a mensuração do resultado econômico e financeiro das empresas (Ferreira et al., 2012).

Segundo Dechow et al. (2010), não há na literatura um método preciso capaz de mensurar a qualidade da informação contábil de maneira confiável ou ampla. Lawson e Wang (2016) apontam dois conjuntos de medidas para se conhecer a qualidade dos ganhos: proxies para persistência de lucros e para riscos de manipulação de resultados. Há de se mencionar, conforme Blaylock et al. (2012) e Blaylock et al. (2015), que a maioria dos autores considera a persistência uma representação de qualidade dos lucros, mas alguns argumentam que ela é um indício de gerenciamento de resultados; se os lucros reportados serão perenes ou não irá depender das ações dos gestores. Por outro lado, há estudos que definem três categorias relacionadas ao Earnings Quality, as quais ampliam essa conceituação para perspectivas do mercado de capital: propriedades dos lucros, indicadores externos e capacidade de resposta dos investidores para os ganhos (Dechow et al., 2010).

Sobre a qualidade dos lucros, as IFRS foram criadas com o intuito de aumentá-la. No Brasil, por exemplo, o Pronunciamento Conceitual Básico R2 (2019), emitido pelo Comitê de Pronunciamentos Contábeis (CPC 00), apresenta as seguintes características qualitativas da informação financeira: fundamentais (relevância e representação fidedigna) e de melhoria (comparabilidade, capacidade de verificação, tempestividade e compreensibilidade). Elas são uma forma de garantir a qualidade dos resultados contábeis divulgados pelas entidades. Dessa forma, a partir da expansão do mercado de ações no Brasil e sua consolidação, torna-se necessária a prestação de informações aos investidores de maneira fidedigna, a fim de garantir a qualidade das demonstrações e a segurança aos seus usuários (Joia \& Nakao, 2014).

Em relação à pluralidade do conceito de Earnings Quality, existem diversos constructos definidos na literatura. Para ilustrar, primeiramente, Basu (1997) analisou o conservadorismo na ótica da contabilidade. Ou seja, em relação ao lucro, como ocorre a diferença temporal entre o reconhecimento das "más notícias" e "boas notícias" pelos investidores. No âmbito do mercado de capitais, a mensuração da qualidade dos lucros associada ao custo do capital é uma importante medida em uma perspectiva macroeconômica, sendo capaz de analisar a precificação, o gerenciamento de 
resultados e futuras condições econômicas da entidade (Kim \& Qi, 2010). Essa definição de value relevance das demonstrações contábeis constitui-se em um fator intrínseco à qualidade dos resultados, que é capaz de influenciar as decisões no que se refere às decisões dos investidores de ações (Tang \& Firth, 2011).

A persistência dos lucros, definida como uma proxy da qualidade dos resultados, tem como principal determinante os accruals e, a partir de sua mensuração, permite a avaliação do valor patrimonial da empresa e suas perspectivas futuras (Dechow et al., 2010). Assim, a persistência dos ganhos é uma medida relevante no que se refere a um fornecimento mais adequado de informações acerca do desempenho financeiro da entidade para a tomada de decisão (Martinez \& Souza, 2015; Martinez, Souza, \& Monte-Mor, 2016).

Segundo Rodrigues, Paulo e Melo (2017), o gerenciamento de resultados relaciona-se com a diferença entre a aplicação do regime de caixa e de competência. $\mathrm{O}$ conceito diz respeito à prática dos gestores em realizar alterações nos relatórios financeiros, não evidenciando as informações de maneira fidedigna e, consequentemente, reduzindo a sua qualidade, o que ocorre, muitas vezes, pelo conflito de interesse entre os acionistas e os gestores da empresa (Ferreira et al., 2012; Healy \& Wahlen, 1999). Diante disso, o estudo do gerenciamento de resultados torna-se um importante meio de avaliar as ações gerenciais, além da qualidade dos lucros (Tang \& Firth, 2011).

Kazemi e Nouri (2012) afirmam que a suavização dos resultados é uma modalidade de earnings management, a qual ocorre a partir de uma atuação intencional do gestor com a finalidade de reduzir a volatilidade dos lucros ou de torná-los persistentes (discussão que vai ao encontro da discussão anterior sobre persistência como proxy de qualidade dos lucros), de forma a condizer com os objetivos e necessidades traçados pela gestão da entidade. Francis et al. (2004), ao estudarem a relação entre os atributos dos lucros e o custo do capital, referem-se à suavização como um constructo mensurado por meio das informações contábeis. Logo, é uma prática realizada pelos gestores de acordo com suas intenções, ou seja, discricionariamente.

O gerenciamento de resultados pode ser compreendido também por meio do "gerenciamento das atividades reais" (Real Earnings Management ou gerenciamento de resultados por atividades operacionais) (Cupertino, Martinez, \& Corta Jr., 2016). Conforme Zang (2012, p. 676), “a manipulação de atividades reais é uma ação intencional para alterar os ganhos reportados em uma determinada direção". Ou seja, ocorre a partir de uma modificação em uma transação do exercício contábil, como, por exemplo, ao realizar cortes em despesas relacionadas às atividades operacionais (Cupertino et al., 2016). Assim, há uma alteração no fluxo de caixa da entidade, o que interfere no desempenho a ser reportado (Katz, 2009). Relacionando as modalidades de earnings management, Zang (2012) concluiu que o gerenciamento das atividades operacionais é realizado em menor escala em comparação ao gerenciamento baseado em accruals, quando se leva em consideração o valor.

Em suma, pode-se concluir que Earnings Quality é uma medida que possibilita a análise do desempenho operacional e de mercado de uma determinada entidade, o que implica diretamente no âmbito dos investimentos (Carvalho et al., 2017). Contudo, são várias as medidas que são utilizadas para mensuração da qualidade dos resultados, o que pode depender do momento, do cenário e das necessidades empresariais.

\subsection{Book-Tax Differences e Earnings Quality}

As BTD podem ser consideradas uma proxy de qualidade dos lucros, ao abrangerem a perspectiva de a administração de determinada entidade realizar ações que visam maximizar o lucro contábil e reduzir o tributário (ou vice-versa) (Ferreira et al., 2012). Nesse contexto, há na literatura diversos estudos que buscaram entender a relação entre as $B T D$ e a qualidade dos lucros.

Hanlon (2005) investigou o papel das BTD pela existência de persistência dos lucros, accruals e fluxos de caixa para o período posterior. A autora concluiu que entidades com maiores $B T D$ possuem menos persistência dos resultados. No referido estudo, houve evidências consistentes a respeito da interpretação dos investidores quanto às BTD como red flag, ou seja, em vista de que tal 
medida reduz a expectativa de informações contábeis confiáveis. Outra investigação a ser considerada no que diz respeito à relação entre a persistência dos ganhos e as BTD é o estágio do ciclo de vida em que a empresa se encontra, pois o aspecto de início ou maturidade de uma entidade influencia tal relação (Drake, 2013).

Ainda sobre a proxy persistência dos lucros e as BTD, Blaylock et al. (2012), com base nos estudos de Hanlon (2005), além de avaliarem a utilidade das BTD para indicar a persistência dos ganhos, analisaram se a variação delas ocorre de acordo com a fonte das diferenças entre o lucro contábil e o tributário.Os resultados deste estudo evidenciaram que, nos casos em que a causa do surgimento das $B T D$ era o gerenciamento de resultados, havia menos persistência dos accruals, em comparação aos casos em que a origem das $B T D$ era a prática de evasão fiscal.

Tang e Firth (2011) apresentaram as BTD como evidências do gerenciamento de resultados e da gestão tributária. Esses autores obtiveram como resultado o fato de que as BTD são capazes de capturar deformidades contábeis, sendo que empresas com fortes incentivos de earnings management possuem maiores BTD Anormais. Assim, segundo os autores, os gestores podem fazer uso das BTD Anormais a fim de distorcer o desempenho econômico. Kraft (2015) investigou em que medida as $B T D$ eram úteis para detecção de práticas de gerenciamento de resultados no que tange aos accruals discricionários durante os anos de 2008 a 2010, período que abrangeu a crise financeira do subprime. Como resultado, o autor evidenciou que as $B T D$, além de serem úteis, estavam proporcionalmente relacionadas com os accruals discricionários e o cumprimento das previsões de lucros (Ferreira et al., 2012).

No que diz respeito ao conservadorismo contábil, Jarboui e Koubaa (2017) o associaram com as $B T D$. Partindo da análise de 28 empresas tunisianas, encontraram evidências de que empresas que possuíam BTD Normais e BTD Anormais apresentavam menos aspectos de conservadorismo contábil, sendo essa uma informação que influencia a decisão de investidores.

Martinez, Francisco Filho e Anunciação (2013) analisaram os efeitos dos componentes permanentes, temporários e totais das $B T D$ nos resultados líquidos e nas despesas tributárias sobre o lucro de empresas brasileiras de capital aberto, entre 2004 e 2011, com ou sem o gerenciamento de resultados. O estudo apontou que o gerenciamento de resultados não tinha relação com as $B T D$ totais, mas havia relação negativa entre as $B T D$ temporárias e os resultados líquidos, e positiva entre as $B T D$ permanentes e as despesas com tributos sobre os lucros. Também com o foco no gerenciamento de resultados, Blaylock et al. (2015) investigaram a relação dessa prática com a conformidade BookTax. A partir do uso de quatro formas diferentes de mensuração de gerenciamento de resultados e uma amostra de 34 países, durante os anos de 1996 a 2007, os autores confirmaram a hipótese de que a maior Book-Tax Conformity estava associada a menor earnings management.

Nos Estados Unidos, houve discussões acerca da eliminação da diferença entre os lucros contábil e tributário, mais conformidade Book-Tax, o que ocasionou investigações por meio de diferentes metodologias. Atwood, Drake, \& Myers (2010) examinaram se o nível de Book-Tax Conformity afetava a persistência dos lucros e a associação entre os resultados e os fluxos de caixa futuros. A partir de uma medida desenvolvida pelos próprios autores, constataram que os lucros possuíam menor persistência e associação com os fluxos de caixa futuros nos casos em que a conformidade era menor. Logo, sugeriram que o aumento da Book-Tax Conformity podia diminuir a qualidade dos lucros.

Por sua vez, Yoon (2008) investigou como a conformidade Book-Tax modificava a relevância e demais componentes dos lucros em diferentes países, sendo esses componentes: vendas, depreciação e despesas com impostos. Conforme a hipótese adotada pelo autor, as evidências do estudo demonstraram que as despesas com vendas, depreciação e impostos eram mais relevantes em países em que havia baixa conformidade fiscal. Houve ainda os estudos com caminhos semelhantes, como os de Sayari e Mugãn (2014), Miiller e Martinez (2016), Lennox, Wu e Zhang (2016), Furtado et al. (2016) e Lambert, Jones, Brazel e Showalter (2017). 
Conforme mencionado, vários estudos relacionaram as BTD com as práticas de gerenciamento de resultados, persistência dos ganhos, value relevance e conservadorismo. Entretanto, no que tange às afetações das BTD na suavização dos resultados e no Real Earnings Management, a literatura atual ainda é incipiente.

Com isso, para balizar essas relações e construir argumentos para a presente pesquisa, são apresentadas investigações similares. Cupertino et al. (2016) demonstraram uma relação negativa entre o gerenciamento por atividades operacionais e a rentabilidade futura das empresas. Blaylock et al. (2015) evidenciaram que maiores Book-Tax Conformity estavam associadas com menor earnings management. Liao e Fu (2015) abordaram a relação entre BTD e earnings management no contexto chinês. Encontraram uma correlação positiva entre as BTD Anormais e o gerenciamento de resultados. Roychowdhury (2006), ao discorrer sobre real earnings management, demonstrou que a tendência para essas práticas prejudica a qualidade dos dados reportados, principalmente por evitar a evidenciação dos dispêndios. O gerenciamento das informações nos custos de produção e despesas eleva os lucros e margens de lucratividade da entidade, mostrando resultados não adequados para os investidores.

Por sua vez, no que diz respeito à suavização dos resultados, Kolozsvari e Macedo (2016) observaram que ela reduziu a persistência dos lucros e, consequentemente, diminuiu a sua qualidade. Francis et al. (2004) evidenciaram que a prática da suavização afeta, de maneira significativa, o custo do capital próprio e o value relevance. Tucker e Zarowin (2006) apresentaram evidências empíricas de que a prática da suavização nas empresas repercutia em preços de ações mais informativos acerca da perspectiva de ganhos futuros.

Com base no exposto, o papel informativo das BTD e sua relação com a qualidade dos lucros tornaram-se temas recorrentes, sobretudo após a adoção das IFRS (Furtado et al., 2016). Assim, por meio das práticas de gerenciamento de resultados, como a suavização e o Real Earnings Management, pressupõe-se que as BTD Anormais afetam negativamente a mensuração da qualidade dos resultados e o preço das ações. A partir do cenário apresentado, as seguintes hipóteses foram formuladas:

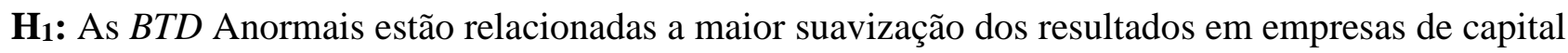
aberto listadas no Brasil.

H2: As BTD Anormais estão relacionadas a maiores práticas de real earnings management em empresas de capital aberto listadas no Brasil.

No tocante à elaboração das hipóteses, é importante discorrer que a suavização dos resultados pode apresentar comportamentos semelhantes ou não ao longo do tempo, o que irá depender do comando da gestão, dos cenários macro e microeconômicos e da situação institucional de um país (Scott, 2012). Outrossim, quando da utilização das proxies suavização e real earnings management, as diferenças entre elas, com a utilização das duas hipóteses, é decorrente do fato de que a primeira representa alterações contábeis que transferem as despesas e receitas quaisquer de um período para o outro, com influência nos fluxos de caixa futuros das entidades. A segunda possui somente manipulações com contas de custos e despesas intimamente relacionadas à produção, e suas afetações ocorrem no período atual do fluxo de caixa (Castro \& Martinez, 2009; Roychowdhury, 2006).

\section{PROCEDIMENTOS METODOLÓGICOS}

\subsection{População, Coleta e Amostra do Estudo}

No presente estudo considerou-se uma população inicial de 555 títulos de ações, sejam preferenciais, ordinários ou outros, que dizem respeito às empresas listadas na Brasil, Bolsa, Balcão (B3). Contudo, foram eliminadas empresas com dados faltantes, aquelas que estão inseridas no segmento financeiro e repetições. Quanto a esta última, na coleta de dados da Economática, as 
empresas podem apresentar mais de um tipo de ação, correspondendo a dados repetidos. Por exemplo, a Vale possui ações ordinárias e preferenciais, que possuem os mesmos valores de ativos e passivos. Para evitar a repetição e a perturbação nas operacionalizações quantitativas, considerou-se somente um tipo de ação por firma. Assim, 228 dados foram retirados da população inicial. Dessa forma, a amostra final do estudo constituiu-se de 327 títulos de ações de diferentes setores.

Para esta pesquisa, foram coletados e utilizados dados referentes ao lucro antes do imposto de renda (LAIR), lucro tributário estimado, despesas de imposto de renda e contribuição social sobre o lucro líquido, equivalência patrimonial, imobilizado e intangível, juros sobre capital próprio e receitas de vendas. Além desses, tem-se também ativo total, fluxo de caixa operacional, clientes, endividamento, rentabilidade sobre os ativos (ROA), valor de mercado, patrimônio líquido, setor, lucro operacional, despesas administrativas, de vendas e gerais, custos de produção (CMV), estoques e lucro líquido. Todas essas informações estão disponíveis na base de dados Economática ${ }^{\circledR}$, sendo contempladas aquelas dos períodos de 2010 a 2018 - período considerado para a harmonização dos dados com a adoção das IFRS no Brasil.

Há de se mencionar que, a partir de um número de observações de 2.943 (nove anos*327 títulos), realizou-se a ponderação das variáveis pelo ativo total, quando necessário. Ademais, utilizouse a winsorização a 1\%, de maneira a evitar a retirada de outliers (ocultação de dados relevantes) e a harmonização dos dados da amostra. A prática da winsorização também é observada nos estudos de Drake (2013), Blaylock et al. (2012) e Dechow et al. (2010).

\subsection{BTD Anormais: Variável Independente}

Após a identificação da amostra do estudo, passou-se a discutir as variáveis e os modelos desta pesquisa. Inicialmente, as $B T D$ totais foram estimadas para cada empresa (i) e em cada ano (t), de 2010 a 2018, como a diferença entre o lucro contábil (LC - Lucros antes dos Impostos sobre o Lucro: LAIR) e o lucro tributário (LT), conforme os modelos de Tang e Firth (2011) e Hanlon (2005). Os cálculos estão indicados a seguir:

$$
\begin{aligned}
& \text { Lucro Contábil }\left(L C_{i, t}\right)=L A I R_{i, t} \\
& \text { Lucro Tributário }\left(L T_{i, t}\right)=\frac{\text { DespIRCS }}{0,34} \\
& B T D \text { total }_{i, t}=\frac{L A I R_{i, t}-L T_{i, t}}{A T_{i, t}}
\end{aligned}
$$

em que: $L A I R_{\mathrm{it}}$ l lucros antes dos impostos de renda e de contribuição social sobre o lucro líquido;

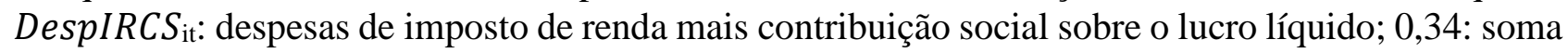
das alíquotas dos impostos sobre o lucro: $15 \%+10 \%$ de imposto de renda e $9 \%$ de contribuição social sobre o lucro líquido; BTD total $\mathrm{it}_{\mathrm{i}}: B T D$ totais para i em t; $A T_{\mathrm{it}}$ : ativo total para i em t.

As $B T D$ foram definidas a partir de seus componentes em Normais e Anormais. Tang e Firth (2011) discutiram que as BTD devem ser explicadas não só pela diferença entre as normativas contábeis e tributárias, mas pelas tendências de práticas de gerenciamento de resultados por parte dos gestores. Assim, a fim de definir as BTD Anormais, as $B T D$ foram divididas em: variáveis que explicam a diferença entre o lucro contábil e o tributário (Normais: variáveis independentes da equação 4); e os resíduos, ou seja, a parcela relacionada à discricionariedade dos gestores (BTD Anormais, $\varepsilon_{i, t}$ da equação 4).

Dessa forma, buscou-se na literatura componentes capazes de explicar a parcela referente à disparidade entre a Contabilidade Financeira e a Contabilidade Tributária. Foram identificados os seguintes itens: juros sobre capital próprio (Brunozi Júnior, 2016; Nakao, 2012); resultados de equivalência patrimonial (Nakao, 2012); imobilizado (Manzon \& Plesko, 2002) e intangível (Tang \& 
Firth, 2011); variação das receitas de vendas (Drake, 2013); e prejuízos fiscais (Manzon \& Plesko, 2002). Tem-se, portanto, a seguinte equação:

$$
\begin{gathered}
B T D_{i, t}=\alpha_{i}+\beta_{1} D_{-} P F_{i, t}+\beta_{2} E Q U I V_{i, t}+\beta_{3} I M O B_{-} I N T_{i, t}+\beta_{4} J C P_{i, t} \\
+\beta_{5} V A R \_R E C_{i, t}+\varepsilon_{i, t}
\end{gathered}
$$

em que: i: empresas; t: anos; $\mathrm{D}_{-} \mathrm{PF}_{\mathrm{i}, \mathrm{t}}$ : representa uma dummy de prejuízos fiscais. Quando os reconhecimentos de despesas de tributos sobre o lucro são positivos, há (1): prejuízos fiscais; (0): não há; $\mathrm{EQUIV}_{\mathrm{i}, \mathrm{t}}$ : resultado de equivalência patrimonial disponível nas demonstrações de resultado, ponderado pelo ativo total em t; IMOB_INT $\mathrm{I}_{\mathrm{i}, \mathrm{t}}$ : valores dos imobilizados e intangíveis obtidos no balanço patrimonial, ponderados pelo ativo total em $\mathrm{t}$; $\mathrm{JCP}_{\mathrm{i}, \mathrm{t}}$ juros sobre capital próprio, ponderados pelo ativo total em $\mathrm{t}$ - para cálculo desta proxy, ver Brunozi Júnior (2016) e Nakao (2012); VAR_REC $\mathrm{i}, \mathrm{t}$ : variação da receita de vendas, ponderada pelo ativo total em t; $\varepsilon_{\mathrm{i}, \mathrm{t}}$ : erro residual da regressão (BTD Anormais); $\alpha_{\mathrm{i}}$ : termo específico da regressão; e $B T D_{\mathrm{i}, \mathrm{t}}$ : variável dependente - são as $B T D$ totais, conforme fórmula (3).

É importante relatar que as relações esperadas das variáveis independentes com as $B T D_{\mathrm{i}, \mathrm{t}} \mathrm{s}$ ão: D_PF $F_{\mathrm{i}, \mathrm{t}}:+,-; \mathrm{EQUIV}_{\mathrm{i}, \mathrm{t}}:+,-; \mathrm{IMOB}_{-} \mathrm{INT}_{\mathrm{i}, \mathrm{t}}:+,-; \mathrm{JCP}_{\mathrm{i}, \mathrm{t}}$ +, e VAR_REC $\mathrm{i}, \mathrm{t}:$ + (Brunozi Júnior, 2016; Nakao, 2012; Tang \& Firth, 2011). As BTD Anormais estão explicadas nos erros apurados, com valores superiores para cima ou para baixo, e indica-se a presença de $B T D$ como decorrentes do gerenciamento de resultados.

\subsection{Variáveis Dependentes e de Controle}

Para as variáveis dependentes deste estudo, foram consideradas proxies de gerenciamento de resultados reais e de suavização dos resultados (earnings smoothness). No que diz respeito às proxies de gerenciamento de resultados reais $(R E M)$, foram utilizadas as proposições de Roychowdhury (2006), que são amplamente adotadas pela literatura científica (Cupertino et al., 2016; Zang, 2012; Maia, Cascudo, Paulo, Levy, \& Melo, 2017).

A partir de Roychowdhury (2006) foram aplicados os modelos de real earnings management para os seguintes componentes contábeis: fluxo de caixa, custos de produção e despesas. Para o cálculo dessas proxies de REM, foram considerados os seguintes modelos:

$$
C F O_{i, t} / A_{i, t-1}=\beta_{0}+\beta_{1}\left(1 / A_{i, t-1}\right)+\beta_{2}\left(S_{i, t} / A_{i, t-1}\right)+\beta_{3}\left(\Delta S_{i, t} / A_{i, t-1}\right)+\varepsilon_{i, t}
$$

em que: i: indivíduos; t: tempo; $C F O_{i, t}$ : fluxo de caixa operacional; $S_{i, t}$ : receita líquida de vendas; $\Delta S_{i, t}$ : variação da receita líquida de vendas em $\mathrm{t}$ e em $\mathrm{t}-1 ; A_{i, t-1}$ : ativo total no período $\mathrm{t}-1 ; \varepsilon_{i, t}$ : resíduos ou erros da regressão.

$$
S G \& A_{i, t} / A_{i, t-1}=\beta_{0}+\beta_{1}\left(1 / A_{i, t-1}\right)+\beta_{2}\left(S_{i, t} / A_{i, t-1}\right)+\varepsilon_{i, t}
$$

em que: i: indivíduos; t: tempo; $S G \& A_{i, t}$ : despesas de vendas, gerais e administrativas; $S_{i, t}$ : receita líquida de vendas; $\varepsilon_{i, t}:$ resíduos ou erros da regressão.

$$
\begin{gathered}
\operatorname{PROD}_{i, t} / A_{i, t-1}=\beta_{0}+\beta_{1}\left(1 / A_{i, t-1}\right)+\beta_{2}\left(S_{i, t} / A_{i, t-1}\right)+ \\
+\beta_{3}\left(\Delta S_{i, t} / A_{i, t-1}\right)+\beta_{3}\left(\Delta S_{i, t-1} / A_{i, t-1}\right)+\varepsilon_{i, t}
\end{gathered}
$$

em que: i: indivíduos; t: tempo; $P R O D_{i, t}$ : custos de produção + variação dos estoques; $\Delta S_{i, t-1}$ : variação da receita líquida de vendas em t-1 e em t-2. As outras variáveis já foram descritas.

Cabe ressaltar que, com base nas equações demonstradas, os erros dos modelos constituemse nas variáveis para o presente estudo. Todos os resíduos, que são as variáveis de interesse, foram multiplicados por -1 para consideração modular (Rodrigues et al., 2017). Assim, quanto maiores esses resíduos, mais práticas de gerenciamento de resultados reais. 
Quanto à obtenção das proxies de suavização, utilizou-se das propostas de Leuz et al. (2003), que empregam métricas com o intuito de capturar as práticas discricionárias dos gestores em diferentes países. Neste estudo foram utilizadas as métricas 1 e 3 da pesquisa dos autores referidos.

$$
E M_{1}=\frac{\sigma L O p}{\sigma F C O}
$$

em que: $E M_{1}$ : métrica $\mathrm{n}^{\mathrm{o}} 1$ de suavização de resultados; $\sigma L O p$ : desvio-padrão do lucro operacional; GFCO: desvio-padrão do fluxo de caixa operacional.

A primeira métrica relaciona o desvio-padrão dos lucros operacionais ao desvio-padrão dos fluxos de caixa operacionais. Conforme Kolozsvari e Macedo (2016), a prática de suavização impulsiona menor variabilidade dos lucros operacionais quando se compara aos fluxos de caixa. Logo, há uma relação inversamente proporcional dessa medida com a suavização (quanto menor o valor encontrado, maior é o nível de suavização). Nos resultados da métrica $\mathrm{n}^{\circ} 1$ evidencia-se a discricionariedade dos gestores para a manipulação dos resultados ao se alterarem informações dos relatórios contábeis (Rodrigues et al., 2017).

A terceira métrica de Leuz et al. (2003) relaciona a taxa média dos accruals totais e o valor absoluto do fluxo de caixa operacional. Dessa forma, tem-se como objetivo, a partir dos lucros, identificar ações discricionárias praticadas (Ribeiro, Carneiro, \& Scherer, 2018).

$$
E M_{3}=\frac{|A T|}{|F C O|}
$$

em que: $E M_{3}$ : métrica $\mathrm{n}^{\mathrm{o}} 3$ de suavização de resultados; $|A T|$ : valor absoluto dos accruals totais, conforme Jones (1991), em tempo t; |FCO|: valor absoluto do fluxo de caixa operacional em tempo $t$. Neste caso, valores superiores indicam a presença de suavização dos resultados.

Adicionalmente, a fim de explicar o gerenciamento de resultados por atividades operacionais e a suavização dos resultados, foram selecionadas as seguintes variáveis de controle: tamanho da empresa (TAM = logaritmo dos ativos totais); desempenho (ROA= lucro líquido/ativo total); endividamento (ENDIV = capital de terceiros/ativo total); valor de mercado sobre o patrimônio líquido $(\mathrm{MKT}=$ valor de mercado/patrimônio líquido); liquidez geral ( $\mathrm{LG}=($ ativo circulante + realizável a longo prazo)/(passivo total)); crescimento das vendas (GTW=(receitas de vendas em t receita de vendas em t-1)/receita de vendas em t-1); e inovação (D_SETI=Dummy com setores de inovação, por exemplo, serviços de tecnologia, química, TI etc.). Pode ocorrer o questionamento de variáveis, como ROA e TAM, serem Bad Controls. No entanto, além de elas serem validadas na literatura, foram feitos testes com e sem elas. Na sua presença, os modelos apresentaram scores mais adequados do desvio do erro da regressão, Durbin-Watson, Akaike e Schwarz.

Com o exposto, a equação desta pesquisa é a seguinte:

$$
\begin{gathered}
\frac{R E M}{S U A V} V_{i, t}=\alpha_{i}+\beta_{1} \text { BTD }_{A N_{i, t}}+\beta_{2} \text { TAM }_{i, t}+\beta_{3} R O A_{i, t}+\beta_{4} E_{N D I V_{i, t}}+ \\
+\beta_{5} M K T_{i, t}+\beta_{6} L G_{i, t}+\beta_{7} G T W_{i, t}+\beta_{8} D_{-} S E T I+\varepsilon_{i, t}
\end{gathered}
$$

em que: $R E M / S U A V_{i, t}$ : variáveis dependentes de gerenciamento de resultados reais e suavização dos resultados; BTD_AN $\mathrm{A}_{\mathrm{i}, \mathrm{t}}$ : São as BTD decorrentes ou como consequência do gerenciamento de resultados. É a parcela discricionária das $B T D$ totais, e $\alpha_{i}$ : termo específico da regressão. As outras variáveis já foram descritas.

Sobre as relações entre variáveis, esperam-se: $B T D$ Anormais com variáveis de: $R E M=+$; $\mathrm{EM} 1=-$; $\mathrm{EM} 3=+$; TAM com variáveis de: $R E M=+$, -; $\mathrm{EM} 1=+$, -; EM3 = +, -; ROA com variáveis de: $R E M=+$; EM1 = - EM3 = +; ENDIV com variáveis de: $R E M=+; \mathrm{EM} 1=-; \mathrm{EM} 3=+; \mathrm{MKT}$ com variáveis de: $R E M=$-; $\mathrm{EM} 1=+$ = $\mathrm{EM} 3=-; \mathrm{LG}$ com variáveis de: $R E M=$-; $\mathrm{EM} 1$ = +; $\mathrm{EM} 3=$-; D_SETI com variáveis de: REM = ?; EM1 = ?; EM3 = ?; e GTW com variáveis de: REM = +; EM1 $=-; \mathrm{EM} 3=+$. 
Para as operacionalizações quantitativas foi utilizado o software Eviews 10® e as técnicas de dados em painel estático (para apuração das variáveis dependentes e BTD Anormais) e quantílica (para as relações entre as BTD Anormais e as variáveis dependentes).

\section{APRESENTAÇÃO E DISCUSSÃO DOS RESULTADOS}

\subsection{Mensurando as BTD Anormais}

Primeiramente, realizou-se a análise das variáveis, $B T D$ Normais, que explicam as $B T D$ totais, apresentadas na Tabela 1. Os resíduos dessa regressão são as BTD Anormais.

Os achados apontam uma relação positiva entre a dummy de prejuízos fiscais e as $B T D$, o que ocorre pelo fato de que a legislação permite deduções no Lucro Real (30\% da base como compensação de prejuízos contábeis anteriores). Logo, há diminuição do Lucro Tributário e, por conseguinte, reflete-se positivamente nas $B T D$. Outrossim, a equivalência patrimonial afeta positivamente, visto que no cálculo do Lucro Contábil ela é inserida como receita, enquanto no Lucro Tributário deve ocorrer sua exclusão. Esse cenário ocorre quando a participação em outras companhias obtém lucros.

Os ativos representados pelo imobilizado e intangível repercutiram em associações negativas com as BTD. Pode-se argumentar que essa perspectiva ocorre quando as amortizações e depreciações contábeis demonstram-se a valores superiores quando comparadas àquelas levadas em consideração tributariamente. Contabilmente, o imobilizado, segundo a International Accounting Standard - IAS 16, e o intangível, conforme a IAS 38, têm seus valores de depreciação e amortização, respectivamente, aplicados sobre o valor de custo ou justo, conforme revisões periódicas de imparidade, valor residual e vidas úteis. Já sob aspectos fiscais, elas são determinadas por valores, taxas ou períodos de vida pré-fixados pela Receita Federal, gerando as BTD.

Tabela 1 - Modelo para apuração das Book-Tax Differences Anormais, período de 2010 a 2018

\begin{tabular}{lcccc}
\hline Variáveis & Coeficientes & Desvio do Erro & T & Valor de p \\
\hline D_PF & 26,81506 & 7,204399 & 3,722039 & $0,0002^{* * *}$ \\
EQUIV & 491,9202 & 280,2132 & 1,755521 & $0,0793^{*}$ \\
IMOB_INT & $-21,27043$ & 9,484349 & $-2,242688$ & $0,0250^{* *}$ \\
JCP & 6,081211 & 6,526173 & 0,931819 & 0,3515 \\
VAR_REC & $-53,74411$ & 12,75135 & $-4,214777$ & $0,0000^{* * *}$ \\
C & $-17,65265$ & 9,134645 & $-1,932495$ & $0,0534^{*}$ \\
\hline $\mathrm{R}^{2}$ & 0,2655 & 2.690 Observ. & Erros-padrões robustos & White \\
\hline
\end{tabular}

Significância das variáveis: *(a 10\%), **(a 5\%) e ***(a 1\%). Fonte: Elaborado pelo autor.

Conforme os dados obtidos, as variações das receitas de vendas afetaram negativamente as $B T D$. Há de se mencionar que, pela amostra, não deveriam ocorrer diferenças de receitas para as empresas, pois praticamente todas as bases de apurações da contabilidade financeira são as mesmas da apuração para fins fiscais. Contudo, conforme discutido por Manzon e Plesko (2002), as BTD causadas pela variação das receitas são decorrentes do fato de que companhias em desenvolvimento tendem a gerenciar os resultados para reduzir os tributos pagos. Koubaa e Anis (2015, p. 96) expõem outro argumento explicativo: a variação nas receitas de vendas pode levar ao reconhecimento variável de perdas estimadas em créditos de liquidação duvidosa. "Nos relatórios contábeis, elas são reconhecidas imediatamente como perdas, levando à redução das receitas anuais e posteriormente à diminuição das despesas de tributos sobre a renda. Nos relatórios fiscais, essas perdas são reconhecidas quando atendidas dadas situações, gerando as BTD”.

Após essas análises, foi possível perceber as variáveis que explicam as BTD Normais (sendo significativas: D_PF, EQUIV, IMOB_INT e VAR_REC), enquanto os resíduos são as BTD Anormais, que apresentaram tendências às médias positivas, de 0,0009, com alto desvio-padrão. Quando as BTD são positivas, ocorre direcionamento para lucros contábeis maiores (gerenciamento de resultados para cima), atraindo shareholders. Para Dridi e Adel (2016), elevar os resultados 
contábeis por meio das BTD Anormais significa atender às pressões do mercado de capitais ou dos credores, pois há a importância de mostrar desempenho positivo nas empresas. Por outro lado, os lucros tributários tendem a ser menores, com indícios de Tax Avoidance. Segundo Kajimoto e Nakao (2018), no Brasil, houve no início da adoção das IFRS uma neutralidade tributária, que pode ter trazido mais liberdade de planejamento tributário agressivo com a possibilidade de minimizar o LT, sem necessariamente também reduzir o LC. Esse cenário pode ter persistido mesmo após o fim dessa neutralidade.

\subsection{BTD Anormais e Suavização dos Resultados}

Na Tabela 2 são apresentados os resultados para as associações entre as BTD Anormais e a suavização dos resultados, no período de 2010 a 2018. A suavização foi determinada com base no estudo de Leuz et al. (2003), ou seja, as métricas EM1 e EM3, conforme as equações 8 e 9.

Inicialmente, verificou-se que, para a EM1, há relação negativa com as BTD Anormais, conforme o esperado, nos modelos OLS e nos quantis de 60 a 90. Essa evidenciação permite deduzir que as $B T D$ Anormais são práticas utilizadas para diminuir a variabilidade dos lucros operacionais em comparação aos fluxos de caixa. A presença de suavização por meio das BTD Anormais pode ser explicada por um nível maior de componentes transitórios contábeis ou fiscais nas operações das empresas, como provisões de perdas ou revisões de valores justos, que amortizam flutuações nos resultados relatados, e/ou a remoção de componentes de caráter permanente, que seriam relevantes informacionalmente quando reportados, mas que trariam mais variabilidade aos lucros (Ribeiro et al., 2018; Dechow \& Schrand, 2004; Dechow et al., 2010). Ademais, é importante discorrer que, quando a suavização é maior (quantis de 60 a 90), as afetações das BTD Anormais são mais significativas. Esses resultados, também percebidos por Dechow e Schrand (2004), ratificam as ações de gerenciamento de resultados extremas, para cima ou para baixo, que afetam a transitoriedade de uma série de resultados.

Argumenta-se que a parcela discricionária das $B T D$ diminui a continuidade e a variabilidade do fluxo de caixa operacional (Brunozi Júnior, 2016; Kolozsvari \& Macedo, 2016). Em consonância, deduziu-se que os gestores ou insiders têm a tentativa de proteger benefícios próprios, com a utilização das $B T D$ Anormais para atingir a performance de sua empresa, com resultados mais constantes. Para Dridi e Adel (2016), a suavização dos resultados é uma maneira de atender aos anseios do mercado de ações, principalmente em mercados pouco desenvolvidos, como o Brasil. Nesse caso, com as $B T D$, os gestores podem omitir mudanças no desempenho econômico usando operações e escolhas sobre o que evidenciar nos relatórios contábeis, mantendo-se a rigidez dos relatos fiscais.

Como relatado anteriormente com Dechow e Schrand (2004) e Dechow et al. (2010), na suavização existem escolhas de inserções de componentes transitórios ou a retirada de permanentes para evitar flutuações dos lucros. Para Dickinson (2011), a relação BTD e EM1 é mais propícia em momentos de mais estabilidade das empresas ao reportar os seus resultados, pois os itens permanentes, como uma perda estimada para créditos de liquidação duvidosa, são mais passíveis de serem retirados pelas empresas.

Com esses achados, houve a não rejeição de $\mathrm{H}_{1}$. Esses fatos sugerem que empresas com BTD Anormais são mais lucrativas continuamente, assim como nas constatações de Koubaa e Anis (2015), Tang e Firth (2011) e Manzon e Plesko (2002), nos casos da Tunísia, China e Estados Unidos, respectivamente. Para ilustrar, uma empresa com lucros em X1 de 90,00 deseja mantê-los em X2, mas suas receitas são menores. Com isso, elas podem reverter provisões ou diminuir suas taxas de constituições para atingir um lucro estável. Para EM3, os resultados não foram significativos.

A relação não significativa de BTD Anormais e EM3 pode ser observada em Ribeiro et al. (2018). Eles explicam que esse tipo de suavização de resultados é mais utilizado por empresas em declínio (não aplicável na amostra desta pesquisa), em que os gestores podem exagerar os ganhos ordinários reportados ou evidenciar operações extraordinárias em instâncias específicas, como uma 
emissão de capital. Assim, pode-se ocasionar a obscuridade do desempenho e a queda da qualidade dos lucros - que não propiciaram uma interferência das BTD Anormais, que são mais presentes em entidades em crescimento e maduras.

Tabela 2 - Resultados das relações entre BTD Anormais e Suavização dos Resultados, período de 2010 a 2018

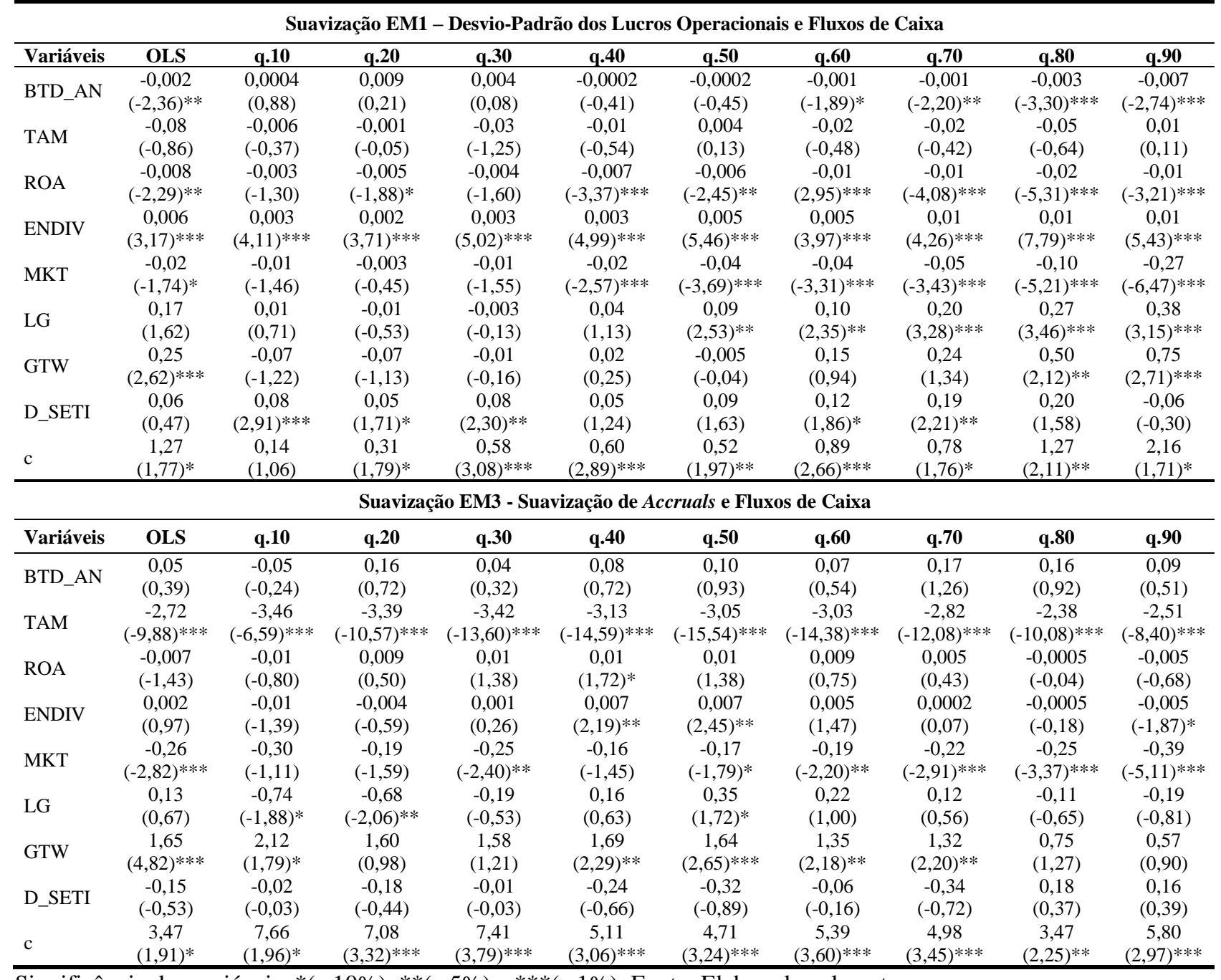

Significância das variáveis: *(a 10\%), **(a 5\%) e ***(a 1\%). Fonte: Elaborada pelo autor.

Com os resultados significativos para EM1, discorre-se que as afetações das BTD Anormais para a suavização também têm explicações na tempestividade de reconhecimentos contábeis e fiscais. Quando existem diferenças temporárias, o tempo é um fator de heterogeneidade entre as normativas contábeis e tributárias (componentes transitórios). No entanto, se elas são utilizadas discricionariamente, podem ser dispositivos que levam ao gerenciamento de resultados, com consequências de assimetria informacional e mudanças nos resultados para a conveniência dos gestores. Argumento similar a esse, Capkun e Collins (2018) visualizaram na relação entre conservadorismo e earnings smoothness.

Sobre as variáveis de controle, deduziu-se, para as duas proxies de suavização dos resultados, que empresas rentáveis tendem a apresentar resultados mais suavizados, sejam eles menores (q.10) ou maiores (q.90). Isso é decorrente da uniformização dos lucros, com a intenção de alcançar desempenhos semelhantes. Normalmente, os ativos das empresas são menos mutáveis do que os resultados, mas, suavizando-os, é possível manter um ROA constante. Nos achados, firmas endividadas tendem a apresentar menos smoothness, de q.10 a q.90. Nesse caso, torna-se mais difícil haver alterações nos lucros para empresas com situações financeiras inadequadas ou insolventes. É 
menos possível a manipulação de componentes transitórios, bem como a retirada de itens permanentes, que já estavam reportados para a instituição credora quando da captação de recursos financeiros.

Em se tratando das outras variáveis, destaca-se que a TAM tendeu a mostrar que empresas maiores suavizam mais os lucros. Ademais, em firmas com market-to-book favorável, a suavização é maior (principalmente nos quantis mais altos). Sobre essa relação entre MKT e suavização, a relação foi contrária à esperada, mas a explicação é que, devido ao mercado de capitais brasileiro ser pequeno e ainda em desenvolvimento, os acionistas podem reconhecer erroneamente práticas de manipulação dos resultados e valorar as ações para cima (Tang \& Firth, 2011; Carvalho, 2016).

As variáveis LG, GTW e D_SETI, quando significativas, em sua maioria, demonstraram associação positiva com a suavização. Para LG e D_SETI, duas deduções são importantes: empresas mais solventes são tendentes a mais alterações em seus reportes para a suavização, pois os gestores tentam evitar reportar perdas e continuar sendo "saudáveis" financeiramente, como foi percebido por Kolozsvari e Macedo (2016); e entidades mais inovadoras evitam a suavização, com o intuito de demonstrar que elas são mais suscetíveis às variações nos resultados por apresentarem grandes despesas em um momento inicial e resultados positivos em longo prazo, mesmo que perdas não sejam desejáveis para as entidades.

\subsection{BTD Anormais e Gerenciamento de Resultados Reais}

Estudos anteriores já demonstraram a existência de associação entre as BTD Anormais e o gerenciamento de resultados (Blaylock et al., 2012; Brunozi Júnior, 2016; Liao \& Fu, 2015), mas são incipientes aqueles que se utilizaram do real earnings management. Partindo disso, na Tabela 3 são apresentados os resultados da relação entre as BTD Anormais e o REM no período de 2010 a 2018.

Primeiramente, para a variável de interesse, as BTD Anormais, notou-se uma associação positiva e significativa com as três proxies de REM (no OLS e nos quantis), conforme esperado. Assim, não houve a rejeição de $\mathrm{H}_{2}$. Dessa forma, tais fatos sugerem, em similar percepção de Anderson, Banker e Janakiramam (2003), que os gestores manipulam deliberadamente os recursos operacionais conforme determinadas circunstâncias e não segundo o volume "normal" ou ordinário de atividades. Esse tipo de gerenciamento de resultados é diferente do feito pelos accruals, pois ocorrem afetações no fluxo de caixa das empresas (Roychowdhury, 2006).

Para a análise dos resultados, tem-se a pressuposição inicial, de acordo com Anderson et al. (2003), de que as variações dos fluxos de caixa, volume de produção, despesas e custos de produção possuem uma relação de contabilização similar, ou seja, todos eles aumentam ou diminuem seus montantes simetricamente na mesma medida e no mesmo sentido. Por exemplo, se há mais custos, existem mais volumes acabados de produtos e fluxos de caixa produzidos e vice-versa. No entanto, com as constatações desta pesquisa, deduziu-se que as BTD Anormais tendem a modificar essa simetria. Uma empresa, ao reduzir seus fluxos de caixa, nas receitas de vendas, utilizando o gerenciamento de resultados, não apresenta uma redução proporcional de custos e despesas, devido às ações discricionárias. Nesse exemplo, podem ter ocorrido decisões de como as empresas calcularam as absorções dos custos para o produto.

Para ratificação de tal fato, no estudo de Zang (2012), houve a constatação de que, nas atividades operacionais de uma entidade com REM, os custos e as despesas aumentam, em média, $0,55 \%$ pela elevação de $1 \%$ nas vendas, mas diminuem $0,35 \%$ pela diminuição de $1 \%$ nas receitas de vendas. Em resumo, as variações não são simétricas e são pelas circunstâncias e não pelas atividades "normais" da organização - para os gestores com o intuito de suavizar, as produções de mercadorias (receitas, custos e despesas) não apresentam um caminho proporcional, mas uma situação artificial desejável para o desempenho que o gestor quer alcançar. Segundo Roychowdhury (2006), essa situação relata como a empresa faz acreditar que determinadas metas foram atingidas no curso normal das operações. 
Para ilustrar a relação BTD Anormais e REM, exemplifica-se a discricionariedade presente nas depreciações produtivas na Contabilidade Financeira em detrimento da fiscal. Por escolhas, a empresa pode utilizar diferenças nas vidas úteis ou valores residuais, por exemplo, para mascarar os resultados apresentados. No mesmo caminho, podem ocorrer atrasos ou adiantamentos nos reconhecimentos das receitas de vendas em relação aos sistemas contábeis e tributários ou a temporalidade de amortizações nos ativos gerados ou nas despesas reconhecidas em pesquisa e desenvolvimento. Com isso, nota-se a presença de escolhas transacionais de desejo dos gestores, que podem ser "artificiais" e fazer acionistas acreditarem no alcance de metas satisfatórias (Zang, 2012; Roychowdhury, 2006), com as BTD para as atividades operacionais e suas tendências para o gerenciamento. Por sua vez, é importante notar que quantis mais altos tendem a demonstrar mais afetações das BTD para "modificar" os resultados por atividades operacionais. Isso pode ser explicado por Cohen e Zarowin (2008), os quais afirmam que as empresas usam as suas capacidades para gerenciar os resultados. Logo, são passíveis de promover sub ou superproduções e/ou grandes ou pequenos descontos nas vendas, ratificando a presença de quantis mais altos percebidos aqui na pesquisa.

Nas análises de variáveis de controle, a variável ROA demonstrou-se positiva e significativa (q. 20 a 60 e q. 80) para a proxy real earnings management quanto aos custos de produção, conforme esperado. No entanto, para as demais variáveis dependentes ocorreu associação negativa, contrária à inicial. Isso pode indicar que as empresas mais lucrativas buscaram não utilizar o REM com o intuito de manter imagem e posição benéfica no mercado, já que o não ofuscamento da informação contábil é um aspecto positivo para os stakeholders/shareholders. Essa percepção vai ao encontro do que afirmam Dechow et al. (2010), que defendem a qualidade dos lucros como ideal para empresas alcançarem resultados satisfatórios no mercado.

Quanto ao crescimento das vendas, a variável GTW demonstrou-se positiva e significativa (no modelo OLS e nos q. 40 a 90) para o gerenciamento de resultados reais relacionado ao fluxo de caixa operacional, conforme esperado. Há a sugestão de que, quanto maior a variação das receitas de vendas, maior a tendência dos gestores em manipular as informações referentes ao fluxo de caixa. Gunny (2005) corrobora esses resultados, uma vez que examinou o REM a partir da redução de preços a fim de impulsionar as vendas no período corrente e reduzir custos de produção. Nas demais proxies, a variável de controle GTW, quando significativa, apresentou-se negativa, com explicação similar à do ROA.

$\mathrm{Na}$ variável TAM, tendeu-se a deduzir que empresas maiores gerenciam mais os resultados (sobretudo nos quantis mais elevados). Ademais, em firmas com market-to-book favorável, o gerenciamento de resultados para as proxies custos de produção é maior (principalmente nos quantis mais altos). Essa evidência, apesar de não confirmar a relação esperada, mostra que gestores praticam gerenciamento de resultados por meio de manipulação de atividades operacionais para valorizar as respectivas ações. Esse fato é corroborado pelo estudo de Roychowdhury (2006), segundo o qual os gestores praticam tais ações com o objetivo de evitar o reporte de perdas anuais na emissão das demonstrações contábeis das empresas. Segundo Santana, Santos, Carvalho Jr. e Martinez (2020), os acionistas possuem sentimentos, alto ou baixo, e para agradá-los os gestores podem gerenciar os resultados para inflar os lucros e influenciar a capacidade de o mercado precificar as ações.

Quanto às outras variáveis, destaca-se que a LG apresentou relações positiva (q. 60 a 90) e negativa (q. 10 a 30) para a proxy de gerenciamento de resultados a partir do fluxo de caixa operacional. Para as demais variáveis dependentes, quanto maior a liquidez geral da empresa, menor a tendência de manipulação dos resultados a partir dos custos de produção, e maior quando se consideram as despesas (q. 20 a 70).

A variável D_SETI apresentou-se negativa e significante para a prática de REM a partir das despesas, ou seja, quando há presença de setor de inovação, menores são as manipulações dos resultados. Assim, as empresas não capitalizam despesas de pesquisa e desenvolvimento para elevar os resultados, sendo fidedignas em seus dados. Roychowdhury (2006) constatou achados diferentes 
em indústrias dos Estados Unidos, as quais utilizaram os dispêndios em pesquisas e desenvolvimento para aumentar os resultados. Ainda, menciona-se que hoje, nas IFRS, é possível os gestores "manipularem" os intangíveis, pois existem no IAS 38 as escolhas em ativar ou alocar aos resultados a formação desse tipo de ativo.

Tabela 3 - Resultados das relações entre BTD Anormais e Gerenciamento de Resultados Reais, período de 2010 a 2018

\begin{tabular}{|c|c|c|c|c|c|c|c|c|c|c|}
\hline \multicolumn{11}{|c|}{ Gerenciamento de resultados reais - FCO } \\
\hline Variáveis & OLS & q.10 & q.20 & q.30 & q.40 & $\mathbf{q . 5 0}$ & q.60 & q.70 & q.80 & q.90 \\
\hline \multirow{2}{*}{ BTD_AN } & 0,0001 & 0,0002 & 0,0001 & 0,0001 & 0,0001 & 0,0001 & 0,0001 & 0,007 & 0,006 & 0,0001 \\
\hline & $(3,39)^{* * *}$ & $(4,32)^{* * *}$ & $(2,93)^{* * *}$ & $(3,19)^{* * *}$ & $(2,94)^{* * *}$ & $(3,34)^{* * *}$ & $(3,43)^{* * *}$ & $(2,13)^{* *}$ & $(1,48)$ & $(2,14)^{* *}$ \\
\hline \multirow{2}{*}{ TAM } & 0,002 & 0,01 & 0,009 & 0,007 & 0,005 & 0,003 & 0,001 & $-0,0004$ & $-0,004$ & $-0,01$ \\
\hline & $(1,15)$ & $(6,75)^{* * *}$ & $(4,58)^{* * *}$ & $(4,10)^{* * *}$ & $(3,35)^{* * *}$ & $(1,98)^{* *}$ & $(1,08)$ & $(-0,27)$ & $(-2,32)^{* *}$ & $(-4,48)^{* * *}$ \\
\hline \multirow{2}{*}{ D_SETI } & 0,0009 & $-0,001$ & $-0,003$ & $-0,003$ & $-0,002$ & 0,0003 & 0,001 & 0,001 & 0,006 & 0,005 \\
\hline & $(0,30)$ & $(-0,45)$ & $(-1,10)$ & $(-1,27)$ & $(-0,97)$ & $(0,10)$ & $(0,51)$ & $(0,37)$ & $(1,53)$ & $(1,26)$ \\
\hline \multirow{2}{*}{ ENDIV } & $-0,001$ & $-0,01$ & $-0,01$ & $-0,01$ & $-0,007$ & $-0,004$ & $-0,0005$ & 0,005 & 0,009 & 0,01 \\
\hline & $(-0,34)$ & $(-4,14)^{* * *}$ & $(-4,07)^{* * *}$ & $(-4,33)^{* * *}$ & $(-2,72)^{* * *}$ & $(-1,67)^{*}$ & $(-0,21)$ & $(1,89)^{*}$ & $(2,63)^{* * *}$ & $(3,58)^{* * *}$ \\
\hline \multirow{2}{*}{ GTW } & 0,01 & $-0,0005$ & 0,006 & 0,007 & 0,009 & 0,01 & 0,01 & $001(261) * * *$ & 0,01 & 0,02 \\
\hline & $(1,92)^{*}$ & $(-0,07)$ & $(0,98)$ & $(1,23)$ & $(1,73)^{*}$ & $(2,09)^{* *}$ & $(2,97)^{* * *}$ & $0,01(2,61)$ & $(2,50)^{* *}$ & $(3,05)^{* * *}$ \\
\hline \multirow{2}{*}{ LG } & 0,002 & $-0,01$ & $-0,01$ & $-0,006$ & $-0,003$ & $-0,004$ & 0,004 & 0,009 & 0,01 & 0,01 \\
\hline & $(1,22)$ & $(-7,45)^{* * *}$ & $(-5,61)^{* * *}$ & $(-3,43) * * *$ & $(-1,52)$ & $(-0,02)$ & $(2,00)^{* *}$ & $(5,02)^{* * *}$ & $(5,82)^{* * * *}$ & $(7,42)^{* * *}$ \\
\hline \multirow{2}{*}{ MKT } & 0,0006 & $-0,001$ & $-0,002$ & $-0,0007$ & $-0,0003$ & 0,0001 & 0,004 & 0,0001 & 0,0008 & $-0,0009$ \\
\hline & $(0,88)$ & $(-1,41)$ & $(-2,21)^{* *}$ & $(-0,08)$ & $(-0,50)$ & $(0,18)$ & $(0,07)$ & $(0,21)$ & $(0,88)$ & $(-0,87)$ \\
\hline \multirow{2}{*}{ ROA } & $-0,0005$ & 0,0006 & 0,0002 & $-0,0001$ & $-0,0003$ & $-0,0006$ & $-0,0009$ & $-0,0009$ & $-0,001$ & $-0,001$ \\
\hline & $(-4,54)^{* * * *}$ & $(2,68)^{* * * *}$ & $(1,28)$ & $(-1,10)$ & $(-2,17)^{* *}$ & $(-2,77)^{* * * *}$ & $(-6,48)^{* * * *}$ & $(-5,81)^{* * *}$ & $(-6,59)^{* * *}$ & $(-6,88)^{* * * *}$ \\
\hline \multirow[b]{2}{*}{$\mathrm{c}$} & $-0,01$ & $-0,09$ & $-0,03$ & $-0,01$ & $-0,01$ & $-0,004$ & $-0,001$ & 0,001 & 0,02 & 0,07 \\
\hline & $(-0,61)$ & $(-4,66) * * *$ & $(-1,72)^{*}$ & $(-1,13)$ & $(-1,22)$ & $(-0,26)$ & $(-0,08)$ & $(0,07)$ & $(1,30)$ & $(2,45)^{* *}$ \\
\hline \multicolumn{11}{|c|}{ Gerenciamento de resultados reais - Custos de produção } \\
\hline Variáveis & OLS & q.10 & q.20 & q.30 & q.40 & q.50 & q.60 & q.70 & q.80 & q.90 \\
\hline \multirow{2}{*}{ BTD_AN } & 0,01 & 0,01 & 0,01 & 0,008 & 0,005 & 0,005 & 0,01 & 0,009 & 0,01 & 0,02 \\
\hline & $(1,88)^{*}$ & $(1,12)$ & $(2,03)^{* *}$ & $(2,33)^{* *}$ & $(1,75)^{*}$ & $(1,67)^{*}$ & $(2,98)^{* * *}$ & $(3,27)^{* * *}$ & $(4,30)^{* * *}$ & $(2,70)^{* * *}$ \\
\hline \multirow{2}{*}{ TAM } & 0,01 & 0,09 & 0,02 & 0,01 & 0,0007 & $-0,01$ & $-0,03$ & $-0,04$ & $-0,07$ & $-0,11$ \\
\hline & $(0,76)$ & $(4,11)^{* * *}$ & $(2,61)^{* * *}$ & $(1,89)^{*}$ & $(0,09)$ & $(-2,60)^{* * *}$ & $(-4,73)^{* * *}$ & $(-5,86)^{* * *}$ & $(-7,75)^{* * *}$ & $(-8,14)^{* * *}$ \\
\hline \multirow{2}{*}{ D_SETI } & $-0,02$ & 0,02 & $-0,01$ & $-0,01$ & $-0,01$ & $-0,01$ & $-0,01$ & $-0,01$ & $-0,001$ & 0,03 \\
\hline & $(-1,06)$ & $(0,93)$ & $(-0,76)$ & $(-2,01)^{* *}$ & $(-2,23)^{* *}$ & $(-1,48)$ & $(-1,77)^{*}$ & $(-1,56)$ & $(-0,15)$ & $(1,33)$ \\
\hline & $-0,07$ & $-0,17$ & $-0,08$ & $-0,08$ & $-0,06$ & $-0,06$ & $-0,04$ & $-0,05$ & $-0,04$ & $-0,03$ \\
\hline ENDIV & $(-2,74)^{* * * *}$ & $(-6,27)^{* * *}$ & $(-6,61)^{* * *}$ & $(-6,93)^{* * *}$ & $(-5,53)^{* * *}$ & $(-5,92)^{* * *}$ & $(-5,27)^{* * *}$ & $(-4,34)^{* * *}$ & $(-2,54)^{* *}$ & $(-1,37)$ \\
\hline & $-0,01$ & $-0,01$ & $-0,06$ & $-0,04$ & $-0,05$ & $-0,04$ & $-0,05$ & $-0,05$ & $-0,05$ & $-0,02$ \\
\hline GTW & $(-0,36)$ & $(-0,34)$ & $(-2,37)^{* *}$ & $(-2,73)^{* * *}$ & $(-3,86)^{* * *}$ & $(-3,22) * * *$ & $(-3,46)^{* * *}$ & $(-3,35)^{* * *}$ & $(-2,08)^{* *}$ & $(-0,51)$ \\
\hline & $-0,05$ & $-0,08$ & $-0,06$ & $-0,05$ & $-0,04$ & $-0,03$ & $-0,02$ & $-0,02$ & $-0,02$ & $-0,05$ \\
\hline LG & $(-2,35)^{* *}$ & $(-3,79)^{* * *}$ & $(-4,91)^{* * *}$ & $(-6,03)^{* * * *}$ & $(-6,71)^{* * *}$ & $(-6,97)^{* * *}$ & $(-4,92)^{* * *}$ & $(-3,43)^{* * *}$ & $(-2,48)^{* *}$ & $(-2,55)^{* *}$ \\
\hline MKT & 0,003 & $-0,007$ & 0,006 & 0,008 & 0,009 & 0,01 & 0,01 & 0,01 & 0,02 & 0,02 \\
\hline MK I & $(0,57)$ & $(-0,55)$ & $(1,74)^{*}$ & $(2,71)^{* * * *}$ & $(3,15)^{* * *}$ & $(4,54)^{* * *}$ & $(4,33)^{* * *}$ & $(4,79) * * *$ & $(5,76)^{* * *}$ & $(3,06)^{* * *}$ \\
\hline ROA & 0,0007 & 0,001 & 0,003 & 0,001 & 0,001 & 0,0009 & 0,0006 & 0,0006 & 0,001 & 0,001 \\
\hline ROA & $(0,74)$ & $(0,66)$ & $(2,50)^{* *}$ & $(1,87)^{*}$ & $(1,89)^{*}$ & $(2,14)^{* *}$ & $(1,72)^{*}$ & $(1,28)$ & $(2,56)^{* *}$ & $(1,38)$ \\
\hline & 0,16 & $-0,13$ & 0,06 & 0,15 & 0,19 & 0,32 & 0,37 & 0,52 & 0,67 & 0,97 \\
\hline $\mathrm{c}$ & $(0,86)$ & $(-0,98)$ & $(0,89)$ & $(2,43)^{* * *}$ & $(3,20)^{* * *}$ & $(5,71)^{* * * *}$ & $(6,71)^{* * *}$ & $(6,99)^{* * * *}$ & $(6,90) * * *$ & $(5,45)^{* * *}$ \\
\hline & & & & erenciamen & to de resulta & los reais - De & pesas & & & \\
\hline Variáveis & OLS & q.10 & q.20 & q.30 & q.40 & q.50 & q.60 & q.70 & q.80 & q.90 \\
\hline & 0,0001 & 0,006 & 0,004 & 0,003 & 0,002 & 0,001 & 0,005 & 0,007 & 0,01 & 0,03 \\
\hline BTD_AN & $(5,64)^{* * *}$ & $(1,22)$ & $(1,22)$ & & $(0,64)$ & $(0,27)$ & $(1,22)$ & $(1,84)^{*}$ & $(3,17)^{* * *}$ & $(3,77)^{* * *}$ \\
\hline TAM & $-0,04$ & 0,03 & 0,01 & 0,007 & $-0,004$ & $-0,01$ & $-0,03$ & $-0,05$ & $-0,11$ & $-0,06$ \\
\hline TAM & $(-4,73)^{* * *}$ & $(4,40)^{* * *}$ & $(2,09)^{* *}$ & $(1,11)$ & $(-0,66)$ & $(-2,19)^{* *}$ & $(-3,86)^{* * *}$ & $(-5,22)^{* * *}$ & $(-6,34)^{* * *}$ & $(-2,43)^{* *}$ \\
\hline & $-0,03$ & $-0,06$ & $-0,05$ & $-0,05$ & $-0,04$ & $-0,04$ & $-0,04$ & $-0,05$ & $-0,05$ & $-0,06$ \\
\hline D_SETI & $(-1,25)$ & $(-33,7)^{* * *}$ & $(-5,15)^{* * *}$ & $(-5,83)^{* * *}$ & $(-5,32)^{* * *}$ & $(-4,68) * * *$ & $(-4,89)^{* * *}$ & $(-4,92)^{* * *}$ & $(-3,90)^{* * *}$ & $(-1,83)^{*}$ \\
\hline & $-0,0003$ & $-0,002$ & $-0,001$ & $-0,001$ & $-0,0008$ & $-0,0008$ & $-0,0007$ & $-0,0007$ & $-0,0004$ & $-0,0002$ \\
\hline ENDIV & $(-2,04) * *$ & $(-2,51)^{* *}$ & $(-3,66)^{* * *}$ & $(-3,92)^{* * *}$ & $(-2,84)^{* * * *}$ & $(-3,08) * * *$ & $(-4,32)^{* * *}$ & $(-4,21)^{* * *}$ & $(-1,51)$ & $(-0,54)$ \\
\hline GTW & $-0,01$ & $-0,02$ & $-0,02$ & $-0,02$ & $-0,009$ & 002 & $-0,02$ & $-0,01$ & $-0,06$ & $-0,05$ \\
\hline GIW & $(-1,69)^{*}$ & $(-0,81)$ & $(-1,42)$ & $(-1,33)$ & $(-0,52)$ & $-0,02(-1,29)$ & $(-1,04)$ & $(-0,78)$ & $(-1,95)^{*}$ & $(-0,71)$ \\
\hline $\mathrm{I} G$ & $-0,0001$ & 0,01 & 0,01 & 0,01 & 0,01 & 0,01 & 0,01 & 0,02 & 0,02 & 0,03 \\
\hline $\mathrm{LG}$ & $(-0,02)$ & $(1,47)$ & $(2,41)^{* * *}$ & $(2,70)^{* * *}$ & $(2,71)^{* * * *}$ & $(2,67)^{* * *}$ & $(1,86)^{*}$ & $(1,90)^{*}$ & $(1,50)$ & $(0,84)$ \\
\hline MKT & 0,004 & 0,003 & 0,004 & 0,003 & 0,008 & 0,01 & 0,02 & 0,03 & 0,05 & 0,05 \\
\hline MKT & $(2,46)^{* *}$ & $(0,67)$ & $(1,27)$ & $(1,04)$ & $(1,88)^{*}$ & $(3,00)^{* * * *}$ & $(3,62)^{* * *}$ & $(6,38)^{* * *}$ & $(5,92)^{* * *}$ & $(7,93)^{* * *}$ \\
\hline & $-0,006$ & $-0,006$ & $-0,005$ & $-0,005$ & $-0,005$ & $-0,006$ & $-0,006$ & $-0,007$ & $-0,007$ & $-0,01$ \\
\hline ROA & $(-14,6)^{* * *}$ & $(-5,27)^{* * *}$ & $(-5,75)^{* * *}$ & $(-5,03) * * *$ & $(-5,11)^{* * *}$ & $(-6,29)^{* * * *}$ & $(-7,32) * * *$ & $(-8,64)^{* * *}$ & $(-5,44) * * *$ & $(-16,58)^{* * * *}$ \\
\hline $\mathrm{C}$ & 0,35 & $-0,26$ & $-0,14$ & $-0,07$ & 0,01 & 0,11 & 0,24 & 0,40 & 0,74 & 0,49 \\
\hline C & $(4,60)^{* * *}$ & $(-3,89)^{* * *}$ & $(-2,59) * * *$ & $(-1,48)$ & $(0,20)$ & $(1,78)^{*}$ & $(3,31)^{* * *}$ & $(4,50) * * *$ & $(5,18)^{* * *}$ & $(2,49) * *$ \\
\hline
\end{tabular}

Significância das variáveis: *(a 10\%), **(a $5 \%) \mathrm{e}^{* * *(a}$ 1\%). Fonte: Elaborada pelo autor. 
Por fim, a variável de controle ENDIV, em sua maioria, relacionou-se negativamente com o $R E M$, indicando que empresas mais endividadas tendem a menor REM. Isso vai de encontro à literatura, pois essa relação, que deveria ser positiva, tem duas explicações: a empresa, quando endividada, gerencia mais os resultados para evitar violar obrigações contratuais; e/ou quando do alto endividamento, as entidades podem gerenciar seus resultados para baixo, para conseguir melhores termos nas renegociações de suas dívidas (Charitou, Louca, \& Vafeas, 2007). Houve relação positiva apenas para a proxy referente ao fluxo de caixa operacional nos quantis q.70 a q.90.

\section{CONSIDERAÇÕES FINAIS}

O gerenciamento dos resultados contábeis e dos tributários tornou-se importante temática para a Contabilidade, principalmente devido aos escândalos contábeis e práticas de evasão fiscal ocorridos mundialmente - a ilustrar, o notório caso da Enron e da Arthur Andersen. Partindo disso, este estudo teve como objetivo analisar as relações entre as BTD Anormais e a suavização dos resultados e o real earnings management em empresas de capital aberto listadas no Brasil. O interesse principal desta pesquisa foi ratificar se as $B T D$ Anormais, como consequência do gerenciamento de resultados, com assimetria informacional, podem aumentar a suavização dos resultados e o REM.

$\mathrm{Na}$ análise da relação entre as $B T D$ Anormais e as práticas de suavização, o presente estudo se voltou para a não rejeição da hipótese $\mathrm{H}_{1}$. A partir dos resultados, houve a sugestão de que as BTD Anormais são utilizadas a fim de diminuir a variabilidade dos lucros operacionais. $\mathrm{O}$ uso de componentes transitórios e/ou a redução de itens permanentes são meios de manter os resultados constantes. Os tributos diferidos e as provisões para perdas são operações que contemplam essas práticas. Há de se destacar que a constância dos resultados é vista pelos gestores como algo que beneficiaria a empresa, proporcionando segurança aos investidores e demonstrando equilíbrio financeiro, em decorrência dessa estabilidade apresentada em suas demonstrações. O objetivo dos gestores é aumentar o valor de mercado e atrair os investidores, e isso acontecerá quando forem atendidas as expectativas destes. Exemplo disso é o cenário atual de crise da saúde mundial, que trouxe variabilidade nos resultados das empresas e saídas recorrentes de investidores, resultando em quedas bruscas na Bolsa de Valores. No Brasil, a baixa acumulada já é de mais de 40\%, aproximadamente.

As ações com objetivo de earnings smoothness refletem os interesses dos gestores, os quais, muitas vezes, não condizem com os anseios dos demais atores. Essas diferenças de desejos e utilidades incentivam ações discricionárias, que podem repercutir na assimetria informacional. No entanto, menciona-se que a suavização é vista por duas vertentes na literatura: i) sendo a suavização um atributo desejável dos lucros, pois para os investidores as constantes mudanças dos lucros pode ser indesejável e indicativo de baixa qualidade dos lucros; ii) os investidores e os credores podem perceber a dispersão dos resultados contábeis como medida de risco. Assim, as empresas com menor variação tendem a atrair mais investidores e créditos a custos mais baixos. Talvez a segunda razão seja a mais provável, por envolver interesses das entidades. Neste último caso, as BTD Anormais são atreladas à tempestividade dos reconhecimentos contábeis e fiscais e à rigidez das legislações tributárias, que impulsionam os gestores a recorrerem à utilização delas para manter seus resultados constantes.

Para o modelo das proxies de gerenciamento de resultados por atividades operacionais, os achados referentes às relações com as BTD Anormais demonstraram ser positivos e significativos, conforme esperado. Logo, a hipótese $\mathrm{H}_{2}$ não foi rejeitada. Tendo em vista o contexto de que os gestores ou insiders podem criar incentivos e divergências e utilizar-se das diferenças contábeis e tributárias de maneira discricionária, conclui-se que as BTD Anormais são meios de alterar as atividades operacionais, considerando as circunstâncias em que a empresa se encontra inserida. Diferentemente da manipulação por accruals, as decisões operacionais têm influência no fluxo de caixa da entidade. Além disso, elas são tomadas ao longo do exercício, de acordo com as atividades 
relativas ao negócio da entidade e os desdobramentos do ciclo operacional. Os accruals normalmente são manipulados, sobretudo entre o encerramento do exercício social e a publicação das demonstrações contábeis.

A partir da não rejeição da hipótese $\mathrm{H}_{2}$, os resultados sugerem que a assimetria entre as normativas contábeis e tributárias se configura como uma lacuna de oportunidade para os gestores realizarem práticas de gerenciamento de resultados reais, como é o caso do cálculo das depreciações ou dos tributos a serem aproveitados nos custos de produção - fazendo-se acreditar, com as escolhas das empresas, que as metas foram alcançados no curso normal dos negócios. Com esse cenário, houve a percepção de que as $B T D$ Anormais tendem a modificar os resultados corretos reportados por parte das empresas, de forma a prejudicar a qualidade dos resultados contábeis, inclusive nas operações rotineiras das empresas, como nas receitas de vendas, custos e despesas produtivas.

Diante do exposto, os resultados desta pesquisa apresentaram contribuições para a literatura ao associarem as BTD Anormais com o gerenciamento por atividades operacionais e a suavização de resultados. Além de essas relações não terem sido exploradas anteriormente, o estudo inovou ao fazer uso da regressão quantílica, tendo apresentado resultados mais robustos em resposta aos outliers e às especificidades das variáveis dependentes. Ademais, considerando o Brasil um país com consideráveis práticas de evasão fiscal e earnings management, o presente estudo representa avanços para a academia frente ao contexto operacional das empresas, com as avaliações pelo REM.

Percebeu-se, como adição, que as BTD podem alterar as atividades produtivas das empresas, que são executadas (e reportadas) segundo a circunstância em que a firma se encontra e os anseios do gestor. Como exemplo, são situações contemplando: a gestão do fluxo de caixa operacional; descontos nos preços para aumentar temporariamente as vendas; a superprodução para relatar custo mais baixo das mercadorias; a redução de despesas para aumentar as margens; as escolhas de métodos para o custeio dos produtos; o investimento em pesquisa e desenvolvimento para influenciar no resultado; e o prazo de reconhecimento da receita. Em outras palavras, a agressividade contábil ou tributária tem implicações para o ciclo operacional das empresas. Nesse caso, as receitas de vendas, despesas e custos têm um caminho de oscilações não proporcionais entre eles, com variações tendentes ao desempenho requerido pela entidade.

Entre as limitações deste estudo, destaca-se o emprego de dados secundários para a aplicação dos modelos, omissão de informações e às modelagens das BTD Anormais e proxies de suavização e real earnings management. Contudo, essas dificuldades não invalidam a presente pesquisa, pois são baseadas em escolhas fundamentadas pelos autores.

Por sua vez, tendo em vista as limitações e buscando aprimorar essa área de estudo, apontamse sugestões para futuras pesquisas. Primeiramente, recomenda-se que elas abranjam outros países, a fim de possibilitar a comparação dos resultados de acordo com as diferentes realidades. Sugere-se também a investigação de outras variáveis que podem ser inseridas para avaliar tanto as BTD Anormais quanto as práticas de earnings smoothness e gerenciamento de resultados reais, como a mediação por ações de governança corporativa ou Top Management Team (TMT).

\section{REFERÊNCIAS}

Anderson, M. C., Banker, R. D., \& Janakiraman, S. N. (2003). Are selling, general, and administrative costs "sticky"? Journal of Accounting Research, 41(1), 47-63.

Atwood, T. J., Drake, M. S., \& Myers, L. A. (2010). Book-tax conformity, earnings persistence and the association between earnings and future cash flows. Journal of Accounting and Economics, 50(1), 111-125.

Ávila, J. R. M. S. (2016). Relação entre Book-Tax Differences e os honorários de auditoria nas companhias abertas brasileiras. 2016. 98 f. Dissertação (Mestrado em Ciências Contábeis) - Programa de PósGraduação em Ciências Contábeis, Universidade Federal de Uberlândia, Uberlândia, MG.

Basu, S. (1997). Changes coming to author affiliations. Journal of Accounting and Economics, 24, 3-37. 
Black, R., \& Nakao, S. H. (2017). Heterogeneity in earnings quality between different classes of companies after IFRS adoption: evidence from Brazil. Revista Contabilidade \& Finanças, 28(73), 113-131.

Blackburne, T., \& Blouin, J. L. (2016). Understanding the informativeness of Book-Tax Differences. SSRN Electronic Journal, Working Paper.

Blaylock, B., Gaertner, F., \& Shevlin, T. (2015). The association between book-tax conformity and earnings management. Review of Accounting Studies, 20(1), 141-172.

Blaylock, B., Shevlin, T., \& Wilson, R. J. (2012). Tax avoidance, large positive temporary book-tax differences, and earnings persistence. The Accounting Review, 87(1), 91-120.

Brunozi Júnior, A. C. (2016). Os efeitos das book-tax diferences anormais na qualidade dos resultados contábeis em empresas de capital aberto listadas no Brasil. 2016. Tese (Doutorado em Ciências Contábeis) - Universidade do Vale do Rio dos Sinos (UNISINOS), São Leopoldo, RS.

Capkun, V., \& Collins, D. W. (2018). The effects of IFRS adoption on observed earnings smoothness properties: the confounding effects of changes in timely gain and loss recognition. European Accounting Review, 27(5), 797-815.

Carvalho, F. L., Camargo, M. B., \& Kalatzis, A. (2017). Earnings quality attributes and investment opportunities for Latin American firms. Advances in Scientific and Applied Accounting, 10(1), 110131.

Castro, M. A. R., \& Martinez, A. L. (2009). Income smoothing, custo de capital de terceiros e estrutura de capital no Brasil. RAM. Revista de Administração Mackenzie, 10(6), 25-46.

Charitou, A., Louca, C., \& Vafeas, N. (2007). Boards, ownership structure, and involuntary delisting from the New York Stock Exchange. Journal of Accounting and Public Policy, 26(2), 249-262.

Chen, E., Gavious, I., \& Yosef, R. (2013). The relationship between the management of book income and taxable income under a moderate level of book-tax conformity. Journal of Accounting, Auditing \& Finance, 28(4), 323-347.

Chi, S. S., Pincus, M., \& Teoh, S. H. (2014). Mispricing of book-tax differences and the trading behavior of short sellers and insiders. The Accounting Review, 89(2), 511-543.

Cohen, D. A., \& Zarowin, P. (2010). Accrual-based and real earnings management activities around seasoned equity offerings. Journal of Accounting and Economics, 50(1), 2-19.

Comitê De Pronunciamentos Contábeis (CPC). Pronunciamento Conceitual Básico CPC 00 (R1): estrutura conceitual para elaboração e divulgação de relatório contábil-financeiro. Disponível em: < http://static.cpc.aatb.com.br/Documentos/147_CPC00_R1.pdf >. Acesso em: 2 jul. 2019.

Costa, P. S. (2012). Implicações da adoção das IFRS sobre a contabilidade financeira e fiscal das companhias abertas brasileiras. 2012. 201 f. Tese (Doutorado em Ciências Contábeis) - Departamento de Contabilidade e Atuária da Faculdade de Economia, Administração e Contabilidade, Universidade de São Paulo, São Paulo, SP.

Cupertino, C. M., Martinez, A. L., \& Costa Jr, N. C. A. D. (2016). Consequências para a rentabilidade futura com o gerenciamento de resultados por meio de atividades operacionais reais. Revista Contabilidade \& Finanças, 27(71), 232-242.

Dechow, P. M., \& Schrand, C. M. (2004). Earnings quality. New York, NY: Research Foundation of CFA Institute.

Dechow, P., Ge, W., \& Schrand, C. (2010). Understanding earnings quality: A review of the proxies, their determinants and their consequences. Journal of Accounting and Economics, 50(2-3), 344-401.

Drake, K. D. (2013). Does firm life cycle explain the relation between book-tax differences and earnings persistence? University of Arizona Eller College of Management Department of Accounting Tucson, AZ, Working Paper.

Dridi, W., \& Adel, B. (2016). Book-Tax Differences and the Persistence of Earnings and Accruals: Tunisian Evidence. Asian Social Science, 12(6), 193-202.

Ecker, F., Francis, J., Kim, I., Olsson, P. M., \& Schipper, K. (2008). A returns-based representation of earnings quality. The Accounting Review, 81(4), 749-780.

Ferreira, F. R., Martinez, A. L., Costa, F. M. D., \& Passamani, R. R. (2012). Book-tax differences e gerenciamento de resultados no mercado de ações do Brasil. Revista de Administração de Empresas, 52(5), 488-501.

Francis, J., LaFond, R., Olsson, P. M., \& Schipper, K. (2004). Costs of equity and earnings attributes. The Accounting Review, 79(4), 967-1010. 
Furtado, L., Souza, J., \& Sarlo Neto, A. (2016). Gerenciamento de Resultados Contábeis à luz das diferenças entre o Lucro Contábil e Tributário (Book-Tax Differences): uma análise de dados em painel balanceado. Revista Ambiente Contábil, 8(1), 115-132.

Gu, Z., Lee, C. W. J., \& Rosett, J. G. (2005). What determines the variability of accounting accruals? Review of Quantitative Finance and Accounting, 24(3), 313-334.

Gunny, K. (2005). What are the consequences of real earnings management? Haas School of Business University of California, Working Paper.

Hanlon, M. (2005). The persistence and pricing of earnings, accruals, and cash flows when firms have large book-tax differences. The Accounting Review, 80(1), 137-166.

Healy, P. M., \& Wahlen, J. M. (1999). A review of the earnings management literature and its implications for standard setting. Accounting Horizons, 13(4), 365-383.

Jarboui, A., \& Koubaa, R. R. (2017). Normal, abnormal book-tax differences and accounting conservatism. Asian Academy of Management Journal of Accounting \& Finance, 13(1), 113-142.

Joia, R. M., \& Nakao, S. H. (2014). Adopción de IFRS y gerenciamiento de resultado en las empresas brasileñas de capital abierto. Revista de Educação e Pesquisa em Contabilidade, 8(1), 22-38.

Katz, S. P. (2009). Earnings quality and ownership structure: The role of private equity sponsors. The Accounting Review, 84(3), 623-658.

Kajimoto, C. G. K., \& Nakao, S. H. (2018). Persistência do lucro tributável com a adoção das IFRS no Brasil. Contabilidade Vista \& Revista, 29(1), 130-149.

Kazemi, H., \& Nouri, S. (2012). The Effects of Earnings Smoothing on Earning Quality and Market Valuing in Environmental Uncertainty. Interdisciplinary Journal of Contemporary Research in Business, 3(10), 338-354.

Kim, D., \& Qi, Y. (2010). Accruals quality, stock returns, and macroeconomic conditions. The Accounting Review, 85(3), 937-978.

Kolozsvari, A. C., \& Macedo, M. A. D. S. (2016). Análise da influência da presença da suavização de resultados sobre a persistência dos lucros no mercado brasileiro. Revista Contabilidade \& Finanças, 27(72), 306-319.

Koubaa, R. R., \& Anis, J. (2015). Book-tax differences: relevant explanatory factors. International Journal of Accounting and Economics Studies, 3(2), 95-104.

Kraft, A. (2015). Management earnings forecasts and book tax differences. International Journal of Economics and Finance, 7(3), 1-23.

Lambert, T. A., Jones, K. L., Brazel, J. F., \& Showalter, D. S. (2017). Audit time pressure and earnings quality: An examination of accelerated filings. Accounting, Organizations and Society, 58, 50-66.

Lawson, B. P., \& Wang, D. (2016). The earnings quality information content of dividend policies and audit pricing. Contemporary Accounting Research, 33(4), 1685-1719.

Lennox, C., Wu, X., \& Zhang, T. (2016). The effect of audit adjustments on earnings quality: Evidence from China. Journal of Accounting and Economics, 61(2-3), 545-562.

Leuz, C., Nanda, D., \& Wysocki, P. D. (2003). Earnings management and investor protection: An international comparison. Journal of Financial Economics, 69(10), 505-527.

Lev, B., \& Nissim, D. (2004). Taxable income, future earnings, and equity values. The Accounting Review, 79(4), 1039-1074.

Liao, Y. H., \& Fu, Q. R. (2015). Research on the Correlation between Book-Tax Difference and Earnings Management. In International Conference on Education Technology and Economic Management (pp. 27-32). Atlantis Press.

Rodrigues, R. M. R. C., Paulo, E., \& de Melo, C. L. L. (2017). Gerenciamento de Resultados por decisões operacionais para sustentar desempenho nas empresas não-financeiras do Ibovespa. Contabilidade Vista \& Revista, 28(3), 82-102.

Maia, R., Cascudo, R., Paulo, E., Levy, C., \& Melo, L. De. (2017). Gerenciamento de Resultados por Decisões Operacionais para Sustentar Desempenho nas Empresas Não Financeiras do Ibovespa. Contabilidade Vista \& Revista, 28(3), 82-102.

Manzon, Jr., G. B., \&Plesko, G. A. (2002). The relation between financial and tax reporting measures of income. Tax Law Review, 55(1), 175-214.

Marques, M. T., Nakao, S. H., \& Costa, P. D. S. (2017). Book-tax differences and capital structure. Revista de Administração Mackenzie, 18(6), 177-200. 
Martinez, A. L., \& Passamani, R. R. (2014). Book-tax differences e sua relevância informacional no mercado de capitais no Brasil. Revista de Gestão, Finanças e Contabilidade, 4(2), 20-37.

Martinez, A. L., \& Bassetti, M. (2016). Ciclo de vida das empresas, book-tax differences e a persistência nos lucros. Revista de Educação e Pesquisa em Contabilidade, 10(2), 148-162.

Martinez, A. L., Francisco Filho, R., \& Anunciação, E. P. (2013). Analysis of the relationship between the components of Book-Tax Differences and annual variations in earnings and tax expenses of firms listed on the BMF\&BOVESPA. Advances in Scientific and Applied Accounting, 6(3), 397-418.

Martinez, A. L., \&Souza, T. B. T. (2015). Book-Tax Differences, Earnings Persistence and Tax Planning before and after the adoption of IFRS in Brazil. In: Congresso Anpcont, 9., Curitiba, PR.

Martinez, A. L., de Souza, T. B. T., \& Monte-Mor, D. S. (2016). Book-tax differences, earnings persistence and tax planning before and after the adoption of IFRS in Brazil. Advances in Scientific and Applied Accounting, 9(2), 162-180.

Mazzioni, S., \& Klann, R. C. (2018). Aspectos da qualidade da informação contábil no contexto internacional. Revista Brasileira de Gestão de Negócios, 20(1), 92-111.

Miiller, D. L., \& Martinez, A. L. (2016). Book-tax difference, earnings management and bond ratings in the Brazilian Market. Revista Universo Contábil, 12(3), 91-109.

Nakao, S. H. (2012). A adoção de IFRS e o legado da conformidade contábil-fiscal mandatória. 62 f. Tese (Livre Docência em Ciências Contábeis) - Departamento de Contabilidade e Atuária da Faculdade de Economia, Administração e Contabilidade, Universidade de São Paulo, Ribeirão Preto, SP.

Naranjo, P., Saavedra, D., \& Verdi, R. S. (2013). Financial Reporting Regulation, Information Asymmetry and Financing Decisions around the World. MIT, Working Paper.

Onezorge, P. V. B., \& Teixeira, A. J. C. (2016). Relação entre Book-Tax Differences e governança corporativa nas empresas listadas na BM\&FBovespa. In: Congresso Anpcont, 10., Ribeirão Preto, SP.

Pinto, A. F., \& de Souza Costa, P. (2019). Book-tax differences e estrutura de capital: uma análise à luz da teoria pecking order. Enfoque: Reflexão Contábil, 38(3), 111-124.

Piqueiras, T. M. (2010). Relação das diferenças entre o lucro contábil e o lucro tributável (Book-Tax Differences) e o gerenciamento de resultados no Brasil. 62 f. Dissertação (Mestrado em Controladoria e Contabilidade) - Departamento de Contabilidade e Atuária da Faculdade de Economia, Administração e Contabilidade - Universidade de São Paulo, Ribeirão Preto, SP.

Ribeiro, F., Carneiro, L. M., \& Scherer, L. M. (2018). Ciclo de vida e suavização de resultados: evidências no mercado de capitais brasileiro. Contabilidade, Gestão e Governança, 21(1), 63-79.

Rodrigues, R. M. R. C., Paulo, E., \& de Melo, C. L. L. (2017). Gerenciamento de Resultados por decisões operacionais para sustentar desempenho nas empresas não-financeiras do Ibovespa. Contabilidade Vista \& Revista, 28(3), 82-102.

Roychowdhury, S. (2006). Earnings management through real activities manipulation. Journal of Accounting and Economics, 42(3), 335-370.

Santana, C. V. S., Santos, L. P. G. D., Carvalho Jr., C. V. D. O., \& Martinez, A. L. (2020). Sentimento do investidor e gerenciamento de resultados no Brasil. Revista Contabilidade \& Finanças, 31(83), 283 301.

Sayari, N., \& Mugãn, F. N. (2014). Comparison of book income and taxable income in terms of value relevance of earnings. World of Accounting Science, 2014(1), 1-21.

Scott, W. R. Financial accounting theory. Toronto, CA: Pearson Canadá, 2012.

Silva, J. P., Bonfim, M. P., Niyama, J. K., \& Silva, C. A. T. (2017). Adoção ao padrão IFRS e earnings quality: a persistência do lucro das empresas listadas na BM\&FBovespa. Revista de Contabilidade e Organizações, 11(29), 46-55.

Tang, T. Y. (2015). Does book-tax conformity deter opportunistic book and tax reporting? An international analysis. European Accounting Review, 24(3), 441-469.

Tang, T., \& Firth, M. (2011). Can book-tax differences capture earnings management and tax management? Empirical evidence from China. The International Journal of Accounting, 46(2), 175-204

Tucker, J. W., \& Zarowin, P. A. (2006). Does income smoothing improve earnings informativeness? The Accounting Review, 81(1), 251-270.

Yoon, S. W. (2008). An international study of the relation between book-tax conformity and the value relevance of earnings components. Journal of International Business Research, 7(2), 31.

Zang, A. Y. (2012). Evidence on the trade-off between real activities manipulation and accrual-based earnings management. The Accounting Review, 87(2), 675-703. 
BOOK-TAX DIFFERENCES ANORMAIS, SUAVIZAÇÃO DOS RESULTADOS E REAL EARNINGS MANAGEMENT EM EMPRESAS DE CAPITAL ABERTO LISTADAS NO BRASIL

Zhou, M. (2016). Does accounting for uncertain tax benefits provide information about the relation between book-tax differences and earnings persistence? Review of Accounting and Finance, 15(1), 65-84. 